\title{
PII S0016-7037(02)00973-0
}

\section{An X-ray absorption fine structure and nuclear magnetic resonance spectroscopy study of gallium-silica complexes in aqueous solution}

\author{
Gleb S. Pokrovski, ${ }^{1} *$ Jacques Schott, ${ }^{2}$ Jean-Louis Hazemann, ${ }^{3}$ François Farges, ${ }^{4}$ and Oleg S. Pokrovsky ${ }^{2}$ \\ ${ }^{1}$ Institut des Sciences de la Terre d'Orléans (ISTO), CNRS (UMR 6113), 1A rue de la Férollerie, 45071 Orléans cedex 2, France \\ ${ }^{2}$ Géochimie, Transferts et Mécanismes, CNRS (UMR 5563)-OMP-Université Paul-Sabatier, 38 rue des Trente-Six Ponts, 31400 Toulouse, France \\ ${ }^{3}$ LGIT and Laboratoire de Cristallographie, CNRS, B.P. 166, 38042 Grenoble, France \\ ${ }^{4}$ Laboratoire des Géomatériaux, Université de Marne la Vallée, 77454 Marne la Vallée cedex 2, France, and Stanford University Environmental \\ Sciences, USA
}

(Received October 17, 2001; accepted in revised form April 22, 2002)

\begin{abstract}
The influence of aqueous silica on gallium(III) hydrolysis in dilute $\left(2 \times 10^{-4} \leq m_{\mathrm{Ga}} \leq 5 \times 10^{-3}\right)$ and moderately concentrated $\left(0.02 \leq m_{\mathrm{Ga}} \leq 0.3\right)$ aqueous solutions was studied at ambient temperature, using high resolution X-ray absorption fine structure (XAFS) and nuclear magnetic resonance (NMR) spectroscopies, respectively. Results show that, in $\mathrm{Si}$-free acidic solutions $(\mathrm{pH}<3)$, $\mathrm{Ga}$ is hexa-coordinated with oxygens of $\mathrm{H}_{2} \mathrm{O}$ molecules and/or $\mathrm{OH}$ groups in the first coordination sphere of the metal. With increasing $\mathrm{pH}$, these hydroxyl groups are progressively replaced by bridging oxygens (-O-), and polymerized Ga-hydroxide complexes form via Ga-O-Ga chemical bonds. In the 2.5-3.5 pH range, both XAFS and NMR spectra are consistent with the dominant presence of the $\mathrm{Ga}_{13}$ Keggin polycation, which has the same local structure as $\mathrm{A}_{13}$. Under basic $\mathrm{pH}(\mathrm{pH}>8)$, Ga exhibits a tetrahedral coordination, corresponding to $\mathrm{Ga}(\mathrm{OH})_{4}^{-}$species, in agreement with previous NMR and potentiometric studies. Major changes in Ga hydrolysis have been detected in the presence of aqueous silica. $\mathrm{Ga}$ is tetra-coordinated, both in basic and acid (i.e., at $\mathrm{pH}>2.7$ ) Si-bearing solutions $\left(0.01 \leq m_{\mathrm{Si}} \leq 0.2\right)$, and forms stable gallium-silicate complexes. In these species, Ga binds via bridging oxygen to $2 \pm 1$ silicons, with an average Ga-Si distance of $3.16 \pm 0.05 \AA$, and to $2 \pm$ 1 silicons, with an average $\mathrm{Ga}-\mathrm{Si}$ distance of $3.39 \pm 0.03 \AA$. These two sets of Ga-Si distances imply the formation of two types of $\mathrm{Ga}$-silicate aqueous complex, cyclic $\mathrm{Ga}-\mathrm{Si}_{2-3}$ species (formed by the substitution of $\mathrm{Si}$ in its tri-, tetra- or hexa-cyclic polymers by $\mathrm{Ga}$ atoms), and chainlike $\mathrm{GaSi}_{2-4}$ species (similar to those found for A1), respectively. The increase in the number of $\mathrm{Si}$ neighbors (a measure of the complex concentration and stability), in alkaline media, with increasing $\mathrm{SiO}_{2}(\mathrm{aq})$ content and decreasing $\mathrm{pH}$ is similar to that for $\mathrm{A} 1-\mathrm{Si}$ complexes found in neutral to basic solutions. At very acid $\mathrm{pH}$ and moderate silica concentrations, the presence of another type of $\mathrm{Ga}-\mathrm{Si}$ complex, in which $\mathrm{Ga}$ remains hexa-coordinated and binds to the silicon tetrahedra via the $\mathrm{GaO}_{6}$ octahedron corners, has also been detected. These species are similar to those found for $\mathrm{Al}^{3+}$ in acid solutions. Thus, as for aluminum, silicic acid greatly hampers $\mathrm{Ga}$ hydrolysis and enhances $\mathrm{Ga}$ mobility in natural waters via the formation of gallium-silicate complexes. Copyright $@ 2002$ Elsevier Science Ltd
\end{abstract}

\section{INTRODUCTION}

Although silicic acid, $\mathrm{Si}(\mathrm{OH})_{4}$, is a major component of natural waters, relatively little attention has been dedicated until recently to its interactions in solution with metals, including aluminum and iron(III). These metals play an important role in a variety of environmental and industrial processes, such as chemical weathering, soil formation or water treatment for purification and consumer use. There is ample evidence that aqueous aluminum/iron(III)-silicate complexes can enhance $\mathrm{Al}$ and $\mathrm{Fe}$ mobility in aquatic systems. As such, they can exert a significant structural and thermodynamic control on the hydrolysis and condensation reactions of these metals and, thus, on the precipitation of oxides and clay minerals (e.g., Olson and O'Melia, 1973; Schwertmann and Thalmann, 1976; Farmer et al., 1977, 1979; Winters and Buckley, 1986; Decarreau et al., 1987; Birchall et al., 1989; Vempati and Loeppert, 1989; Browne and Driscoll, 1992; Exley and Birchall, 1992, 1993; Xu and Harsh, 1993; Konhauser and Ferris, 1996; Mayer and

* Author to whom correspondence should be addressed (gleb@cnrsorleans.fr).
Jarrell, 1996; Doelsch et al., 2000). During the last years, different techniques including solubility measurements, potentiometric titrations and spectroscopic analyses were combined to establish the nature, structure and stability of the aqueous complexes formed between $\mathrm{Al}$ or Fe and silicic acid (Farmer and Lumsdon, 1994; Pokrovski et al., 1996, 1998, 2001; Salvi et al., 1998; Gout et al., 1999, 2000; Doelsch et al., 2000). The aim of the present work is to combine ${ }^{71} \mathrm{Ga}$ NMR and Ga $\mathrm{K}$-edge XAFS measurements to characterize the local environment around $\mathrm{Ga}$ in dilute aqueous solutions with various $\mathrm{Si} / \mathrm{Ga}$ ratio values and over a wide range of $\mathrm{pH}$.

Because both $\mathrm{Ga}$ and $\mathrm{Al}$ are located in the third column of the Pediodic Table, they exhibit many similar chemical properties, and often close geochemical behavior. The general features of $\mathrm{Ga}$ and $\mathrm{Al}$ hydrolysis and polymerization in aqueous solution are also similar (Baes and Mesmer, 1976). With increasing $\mathrm{pH}$, both metals hydrolyze with progressive formation of $(\mathrm{Al}, \mathrm{Ga}) \mathrm{OH}_{1-3}$ monomeric species (Bénézeth et al., 1997; Diakonov et al., 1997), and polymeric polycations at slighly acid $\mathrm{pH}$ leading to the precipitation of $\mathrm{Al}$ and $\mathrm{Ga}$ oxy-hydroxides. At neutral and basic $\mathrm{pH}$, these phases easily dissolve by forming $\mathrm{Al}(\mathrm{OH})_{4}^{-}$and $\mathrm{Ga}(\mathrm{OH})_{4}^{-}$species, respectively. Struc- 
tural aspects of Ga hydrolysis, especially in the presence of aqueous silica, are however poorly known. Knowledge of $\mathrm{Ga}$ and $\mathrm{Al}$ coordination and local atomic environment in their hydroxide and silicate complexes is necessary for understanding the mobility of these metals, the formation of their minerals, and the role of aqueous silica in these processes.

In many studies dealing with the aqueous speciation of aluminum and gallium, nuclear magnetic resonance (NMR) was the chosen spectroscopic method due to its sensitivity to changes in the coordination of these elements, and it has provided clear evidence for the formation of polymeric species in which $\mathrm{Al}$ or $\mathrm{Ga}$ are both tetra-, and hexa-coordinated (e.g., Akitt et al., 1972; Akitt and Elders, 1988; Thomas et al., 1993; Faust et al., 1995; Öhman and Edlund, 1996; and references therein). However, because both metals exhibit broad NMR resonances in aqueous solution, the assignment of the octahedral signal provided by their monomeric and polymeric complexes is uncertain. X-ray absorption fine structure (XAFS) spectroscopy is the only direct in situ method which can provide quantitative information at the atomic scale about the local structural environment of metals in any system, including their aqueous complexes (ligand's identity and number, and interatomic distances). Although XAFS spectroscopy of $\mathrm{Al}$ (atomic weight 27) is at present limited to high concentrations $(>0.1$ $\mathrm{m}$ ), gallium (atomic weight 70) can be studied by XAFS spectroscopy at concentrations as low as $10^{-5}-10^{-4} \mathrm{~m}$ using the third generation synchrotron sources. Although such concentrations are higher than those usually encountered for $\mathrm{Ga}$ in natural waters, they are low enough to significantly slow down Ga polymerization and precipitation, and to allow the accurate characterization of $\mathrm{Ga}-\mathrm{Si}$ interactions (complexation) which can be easily masked by $\mathrm{Ga}-\mathrm{Ga}$ condensation and solid phase precipitation at higher concentrations. Therefore, XAFS results obtained for $\mathrm{Ga}-\mathrm{Si}$ interactions can be used for understanding the behavior of this trace element in natural waters. Such data are also believed to produce useful analogies for better understanding Al-Si complexation, based on the similar chemical behavior of $\mathrm{Al}$ and $\mathrm{Ga}$. The combination of the ${ }^{71} \mathrm{Ga}$ NMR and Ga $K$-edge XAFS spectroscopic measurements presented in this study provides new insights into the structure of the aqueous species that form during gallium hydrolysis in the presence of silicic acid.

\section{MATERIALS AND METHODS}

\subsection{Sample Preparation}

Ga-bearing aqueous solutions for XAFS and NMR experiments were prepared by dissolving weighted amounts of hydrated gallium nitrate $\left(\mathrm{Ga}\left(\mathrm{NO}_{3}\right)_{3} \cdot 9 \mathrm{H}_{2} \mathrm{O}, 99.99 \%\right.$, Aldrich Chemicals) in doubly deionized water (MilliQ system). The water content of the initial salt was checked by analyzing solutions by flame atomic absorption and was found to be close to the theoretical value within $2 \mathrm{wt}$. \%. The $\mathrm{pH}$ of the solutions was adjusted by adding $1 \mathrm{M}$ nitric acid $\left(\mathrm{HNO}_{3}\right)$ or $1 \mathrm{M}$ tetramethylammonium hydroxide $\left(\left(\mathrm{CH}_{3}\right)_{4} \mathrm{NOH}\right)$ Titrisol solutions, and measured before and after experiment with a combination $\mathrm{pH}$ glass electrode (SCHOTT-H61) calibrated on the activity scale using the NIST tartrate, phthalate, phosphate, and borate buffers $\left(\mathrm{pH}_{20}{ }^{\circ} \mathrm{C}=1.69,4.00,6.87\right.$, and 9.21 , respectively) and $0.1 \mathrm{~m} \mathrm{HCl}$ and $0.01 \mathrm{~m} \mathrm{NaOH}$ solutions $\left(\mathrm{pH}_{20}{ }^{\circ} \mathrm{C}=1.11\right.$ and 12.12, respectively). Silicic acid $\left(\mathrm{H}_{4} \mathrm{SiO}_{4}\right)$ was introduced in the Ga-bearing solutions as weighted amounts of a $0.67 \mathrm{~m}$ $\mathrm{Si}$ solution, prepared by equilibration of amorphous silica powder $\left(\mathrm{SiO}_{2} \cdot 2.2 \mathrm{H}_{2} \mathrm{O}\right)$ at ambient temperature in a $0.5 \mathrm{~m}$ tetramethylammonium hydroxide solution. Tetramethylammonium and nitrate were cho- sen in this study as the major cation and anion, respectively, because of their very low complexing affinity for metals in aqueous solution (Baes and Mesmer, 1976; Wesolowski et al., 1995) even in comparison to other commonly used background ions $\left(\mathrm{Na}^{+}, \mathrm{K}^{+}, \mathrm{Cl}^{-}\right)$. The influence of $\mathrm{NO}_{3}^{-}$and $\left(\mathrm{CH}_{3}\right)_{4} \mathrm{~N}^{+}$on $\mathrm{Ga}$ hydrolysis and $\mathrm{Ga}-\mathrm{Si}$ complexing in solution can thus be neglected when analyzing XAFS and NMR spectra. To avoid possible polymerization and/or precipitation during sample preparation, solutions were vigorously stirred using a magnetic stirrer, and then immediately filtered through a $0.2-\mu \mathrm{m}$ Millipore filter. Measurements were performed within 1 to 2 hours after solution preparation. $\mathrm{Ga}$ and $\mathrm{Si}$ concentrations in the experimental solutions used for XAFS experiments ranged from 0.0002 to $0.005 \mathrm{~m}$ and 0.01 to $0.10 \mathrm{~m}$, respectively. For NMR measurements, more concentrated solutions containing 0.02 to $0.3 \mathrm{~m} \mathrm{Ga}$ and 0.05 to $0.2 \mathrm{~m} \mathrm{Si}$ were used. The $\mathrm{pH}$ of the solutions in both types of experiments ranged from 1 to 11 , which correspond to $\mathrm{H} / \mathrm{Ga}$ and $\mathrm{OH} / \mathrm{Ga}$ hydrolysis ratios from 100 to 0 and 0 to 4.5 , respectively, depending on Ga concentration. Monomeric silica, total $\mathrm{Si}$ and total $\mathrm{Ga}$ concentrations were determined using the molybdate blue colorimetric method (Koroleff, 1976), ICP-MS (inductively coupled plasma mass spectrometry) (see details in Pokrovski and Schott, 1998), and flame atomic absorption spectroscopy (see Bénézeth et al., 1997). Analyses performed on solutions before and after XAFS and NMR spectra acquisitions showed no changes in $\mathrm{Si}$ and Ga concentrations in the limit of the analytical uncertainties $( \pm 5 \%$ of total concentration). Silicic acid remained essentially monomeric $(>90 \%$ of total $\mathrm{Si}$ ) in the alkaline solution after experiments. In acid solutions, silica polymerization occurred rapidly (within several min.), and more than $50 \%$ of total $\mathrm{Si}$ was found to be polymerized after measurements in the solutions with high aqueous silica concentrations. In some solutions with the highest $\mathrm{Si}$ concentration $(0.1 \mathrm{~m})$ at nearneutral $\mathrm{pH}$, a silica gel was observed after measurements, depending on $\mathrm{pH}$ and time of measurement. However, the structural environment of Ga derived from the XAFS spectra was found to be only slightly sensitive to silica polymerization (see below). No significant $\mathrm{pH}$ changes $( \pm 0.1-0.2 \mathrm{pH}$ unit) were recorded after experiments for most solutions. Although the majority of solutions at $\mathrm{pH}$ higher than 3 were significantly supersaturated with respect to $\mathrm{Ga}$ oxy-hydroxides $(\alpha$ $\left.\mathrm{GaOOH}, \mathrm{Ga}(\mathrm{OH})_{3}\right)$, the constancy of $\mathrm{Ga}$ and $\mathrm{Si}$ concentrations and $\mathrm{pH}$, measured before and after experiments on solutions filtered through $0.2-\mu \mathrm{m}$ membrane filters, indicates that no precipitation of Ga phases occured during measurements. The presence of nanoparticles of these and other solid phases, which could have passed through the $0.2-\mu \mathrm{m}$ filter, can also be excluded. Such particles would have inevitably introduced fluctuations of $\mathrm{Ga}$ concentration on the beam passage through the aqueous sample, so that the resulting X-ray absorption spectrum would have exhibited significant irregularities and much higher noise than that for a homogeneous solution. As it can be seen below, XAFS scans recorded in this study for all solutions (except for $0.0002 \mathrm{~m} \mathrm{Ga}, \mathrm{pH}=5$; see Sect. 4.2.1), were similar for each given sample and without suspicious noise and flaws, thus demonstrating that no solid phase formation occured in the experimental solutions.

\subsection{NMR Spectra Acquisition}

NMR experiments were performed using a Bruker AH 300 WB spectrometer, equipped with a $10-\mathrm{mm}$ multinuclear probehead. To perform quantitative measurements, $3 \mathrm{~mL}$ of solution were placed in a 10-mm inner-diameter glass tube. A 3-mm glass tube filled with $\mathrm{D}_{2} \mathrm{O}$ and inserted in the $10-\mathrm{mm}$ tube was used as field-frequency lock. ${ }^{71} \mathrm{Ga}$ one-pulse experiments were performed at $91.49 \mathrm{MHz}$ with a $\pi / 4$ pulse duration of $5 \mu \mathrm{s}$ and a recycle time of $1 \mathrm{~s}$. Between $10^{3}$ and $2 \times 10^{5}$ acquisitions were performed depending on aqueous Ga concentration and the intensity of the signal. A line broadening of $35-50 \mathrm{~Hz}$ was applied, and the spectra were referenced to a $0.5 \mathrm{M}$ aqueous solution of $\mathrm{Ga}\left(\mathrm{NO}_{3}\right)_{3}\left(\left[\mathrm{Ga}\left(\mathrm{H}_{2} \mathrm{O}\right)_{6}\right]^{3+}\right)$. The concentration of the $\mathrm{Ga}_{13}$ polycation and ${ }^{\left[{ }^{[6} \mathrm{Ga}\right.}$ hydroxide complexes in acid silica-free solutions was determined by filling the 10 -mm insert tube with a $0.026 \mathrm{M} \mathrm{Ga}(\mathrm{OH})_{4}^{-}$ solution containing $\mathrm{D}_{2} \mathrm{O}$, and by measuring the relative areas of the peaks at $222\left[\mathrm{Ga}(\mathrm{OH})_{4}^{-}\right], 174 \mathrm{ppm}$ (central ${ }^{[4]} \mathrm{Ga}$ in $\mathrm{Ga}_{13}$ polycation) and $0 \mathrm{ppm}$ (octahedral gallium aquoion and hydroxide complexes). (See Figs. 1 and 2.) 


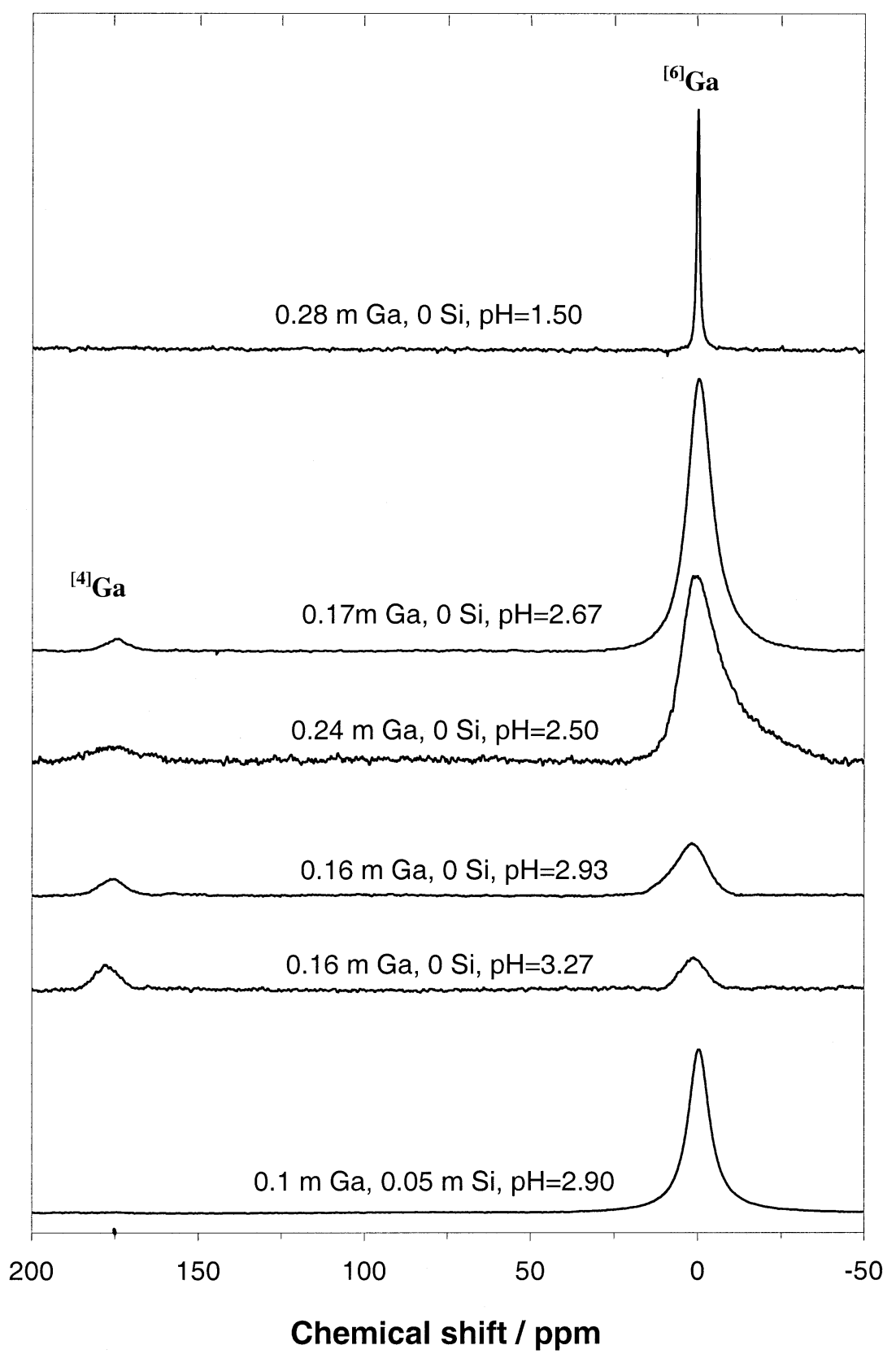

Fig. 1. Evolution of ${ }^{71} \mathrm{Ga}$ NMR spectra of gallium nitrate acid solutions as a function of $\mathrm{pH}$ and $\mathrm{SiO}_{2}(\mathrm{aq})$ concentration. Peaks around 0 and $174 \mathrm{ppm}$ account, respectively, for octahedral and tetrahedral $\left(\mathrm{Ga}_{13}\right)$ gallium geometry in its aqueous complexes.

\subsection{XAFS Spectra Acquisition and Data Reduction}

XAFS spectra (including the X-ray absorption near edge structure region or XANES, and the extended X-ray absorption fine structure region or EXAFS) were collected at ambient temperature $\left(20 \pm 1{ }^{\circ} \mathrm{C}\right)$ in the fluorescence mode at the Ga $K$-edge $(\sim 10,370 \mathrm{eV})$ over the energy range $10,200-11,800 \mathrm{eV}$ on the collaborative research group IF BM32 beam line at the European Synchrotron Radiation Facility (ESRF, Grenoble, France). The storage ring was operated in the multibunch filling mode at $6 \mathrm{GeV}$ with a $200 \mathrm{~mA}$ current. The beam energy was selected using a $\mathrm{Si}(111)$ double crystal monochromator with sagittal focussing. The fluorescence spectra were collected using a Canberra 30-element solid state detector. The solutions were placed in a special Teflon cell with kapton-film windows. The cell handling and spectra acquisition procedure were similar to those described in Pokrovski et al. (2000). In order to obtain the necessary signal-to-noise ratio for quantifying next-nearest neighbors $(\mathrm{Ga}, \mathrm{Si})$ around the absorbing $\mathrm{Ga}$ atoms, 3 to 6 scans (of $\sim 50 \mathrm{~min} / \mathrm{scan}$ data collection time) for each solution were performed up to high $k$ values $\left(14-14.5 \AA^{-1}\right)$. After acquisition, all scans for each sample were carefully inspected for each solid state detector and, if found reasonably free of beam intensity fluctuations and other flaws, were added together. Solid gallium hydroxide, $\alpha-\mathrm{GaOOH}$, and nitrate, $\mathrm{Ga}\left(\mathrm{NO}_{3}\right)_{3} \cdot 9 \mathrm{H}_{2} \mathrm{O}$, which can serve as model compounds for Ga local environment, were recorded in the transmission mode to exclude self-absorption effects.

XAFS data analysis were performed using the SEDEM (Aberdam, 1998) and XAFS2.6 (Winterer, 1997) packages. Both programs have 


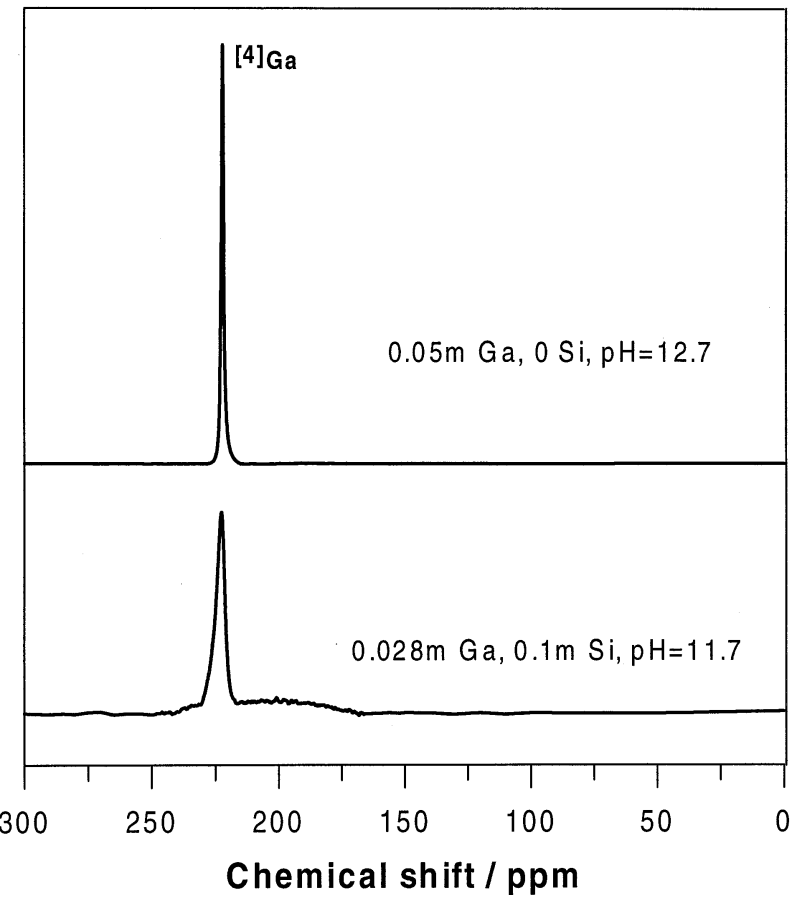

Fig. $2 .{ }^{71} \mathrm{Ga}$ NMR spectra of gallium nitrate basic solutions with and without aqueous silica. The peaks correspond to tetrahedral Ga coordination in its hydroxide and silicate complexes.

produced the same results in the limit of the uncertainties when extracting structural information for the Ga coordination shells (see below). The analysis of the XANES data was performed in the region of $100 \mathrm{eV}$ below and $200 \mathrm{eV}$ above the absorption edge using a procedure similar to that of Farges et al. (1996a). First, the before-edge spectral region $(10,200-10,300 \mathrm{eV})$ was fitted using a Victoreen function and subtracting this as background absorption. Then, the XAFS spectra were normalized for atomic absorption, based on the average absorption coefficient of the spectral region 10,370-10,600 eV. The spectra obtained were superposed to compare the white line position and the shape of peaks for different solutions (e.g., Fig. 3).

EXAFS spectra were analyzed as previously described in Pokrovski et al. (2000), and following the "standard" procedure (Teo, 1986). Energies were recalculated into $k$ space $\left(\AA^{-1}\right)$ with $E_{0}$ (i.e., the energy where $k$ is zero) arbitrarily chosen at zero of the edge first derivative. The $k^{2}$-weighted EXAFS spectra were Fourier transformed over the $k$ range from 3 to $14 \AA^{-1}$ a Kaiser-Bessel window function (Bonnin et al., 1985) with $\tau$ values of 2.5 in order to reduce termination effects in the Fourier transform (FT) (e.g., Figs. 4b and 5b). To extract structural information, one or several FT peaks were back-transformed into momentum space (inverse Fourier transform, IFT) (Figs. 6 and 7). Modeling of these EXAFS oscillations (IFT) by least-square fitting gives average structural parameters for the Ga environment (identity of first and second (if present) neighbor atoms, distances $(R)$ between $\mathrm{Ga}$ and their neighbors, average coordination numbers $(N)$, and the DebyeWaller factors (DW, $\sigma^{2}$ ) which is a measure of disorder). Raw EXAFS spectra were also fitted with multiple shells (Fig. 8); they produced values of structural parameters similar to those extracted from fits of individual IFTs. For most spectra of Ga-Si solutions with weak second and third shell contributions, fits of the total EXAFS spectrum were, however, less stable and exhibited larger uncertainties than those for the individual-shell IFTs. Consequently, the results of the latter fits were considered to be more reliable and they are reported in this study (Tables 1 and 2). Theoretical backscattering amplitude and phase-shift functions for $\mathrm{Ga}-\mathrm{O}, \mathrm{Ga}-\mathrm{Ga}$, and $\mathrm{Ga}-\mathrm{Si}$ pairs were computed using the FEFF 6.01 ab initio code (Ankudinov and Rehr, 1997; Zabinsky et al., 1995), assuming the local structure around $\mathrm{Ga}$ in $\alpha_{-}{ }^{[6]} \mathrm{GaOOH}$ (Pye et al., 1977) and a ${ }^{[4]} \mathrm{Ga}$-zeolite, $\mathrm{Na}_{3}\left(\mathrm{Ga}_{3} \mathrm{Si}_{3} \mathrm{O}_{10}\right)\left(\mathrm{H}_{2} \mathrm{O}\right)_{4}$ (Nenoff et al.,

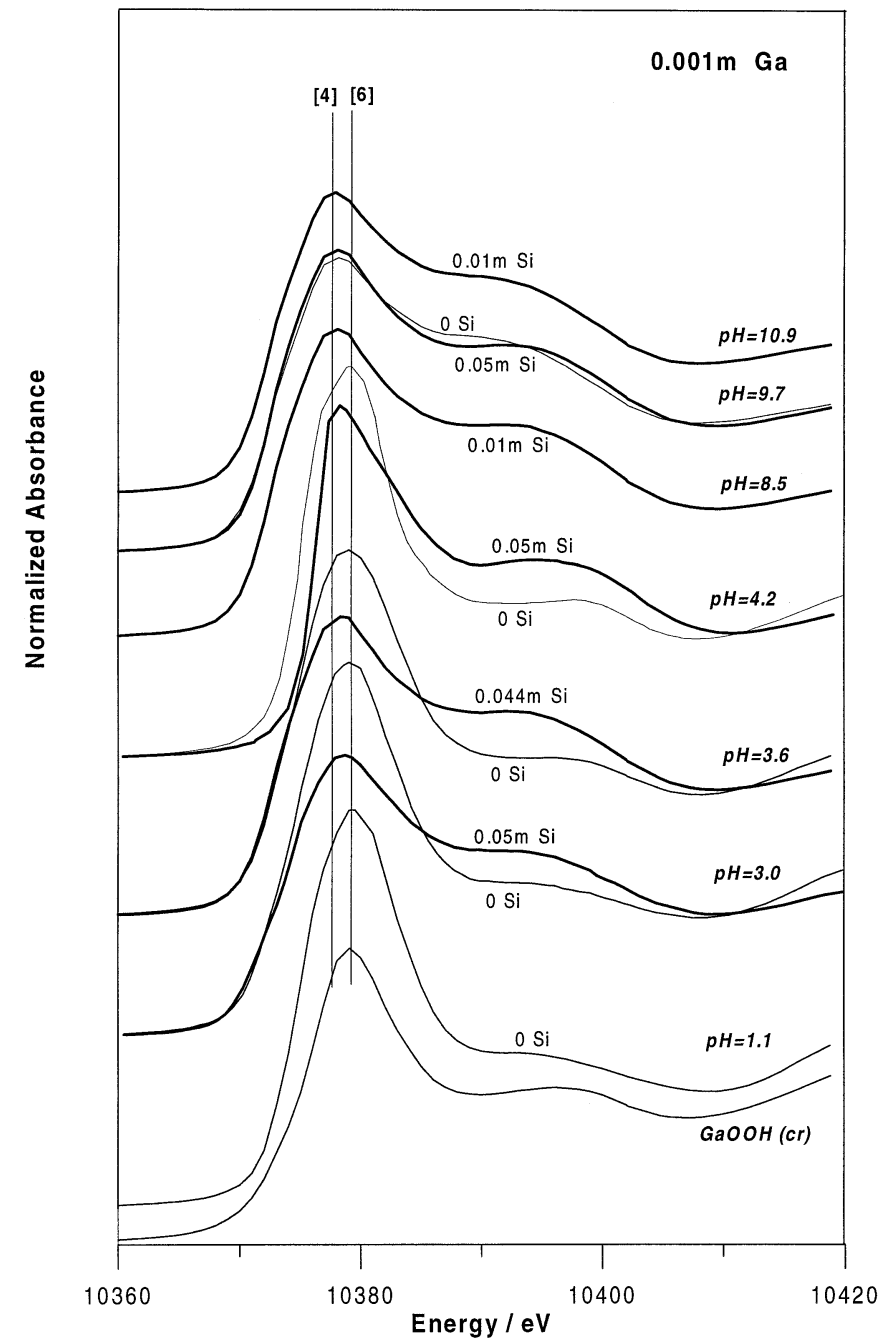

Fig. 3. Normalized XANES spectra of selected $0.001 \mathrm{~m}$ Ga nitrate solutions with (thick curves) and without (thin curves) aqueous silica. Vertical lines denote shifts in edge-crest energy corresponding to the octahedral ( $\alpha-\mathrm{GaOOH}$ and silica-free acid solutions) and tetrahedral (Si-free basic solutions and Si-bearing acid and basic solutions) Ga local geometry.

1994). The amplitude reduction factor $S^{2}{ }_{0}$ and Debye-Waller factors were set to 1 and 0 , respectively, in the calculations of these functions. The validity of the calculated amplitude and phase functions was checked by fitting EXAFS spectra of $\alpha-\mathrm{GaOOH}$ and $\mathrm{Ga}\left(\mathrm{NO}_{3}\right)_{3} \cdot 9 \mathrm{H}_{2} \mathrm{O}$. The influence of possible disorder (thermal and static) in determining structural parameters was checked using an anharmonic approach consisting of adding, in the expression of the pair-correlation function between absorbing element and their neighbors, third- $\left(C_{3}\right)$ and fourthorder $\left(C_{4}\right)$ cumulants accounting for the anharmonicity (Crozier et al., 1988; Farges, 1996; Farges et al., 1996b; Soldo et al., 1998). The typical values of $C_{3}$ and $C_{4}$ found when fitting our IFT spectra for the Ga first coordination shell were of the order of $10^{-4}$, and did not change significantly $R$ and $N$ values derived from least-square fits without cumulants. As a result, in order to reduce the number of variables and thus the uncertainties on the derived parameters, we decided not to use the anharmonic approximation when extracting $R, N$, and $\sigma$ values for all $\mathrm{Ga}$ atomic shells. The influence of possible multiple scattering phenomena (MS) within the Ga first coordination shell on the EXAFS spectra was also tested using the FEFF code. With the exception of the most acid $\mathrm{Ga}$ solutions ( $\mathrm{pH} \sim 1$ ), MS contributions from the 


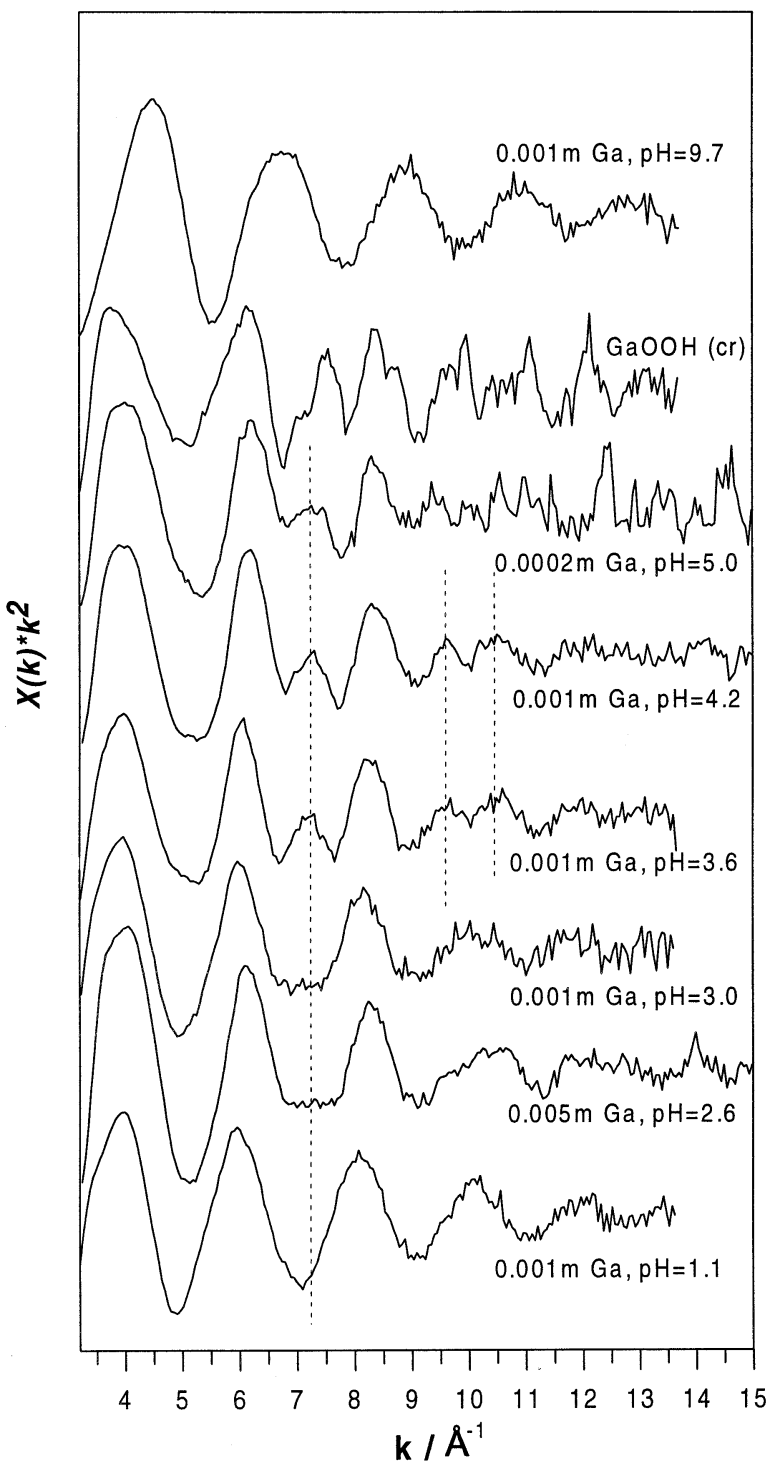

(a)

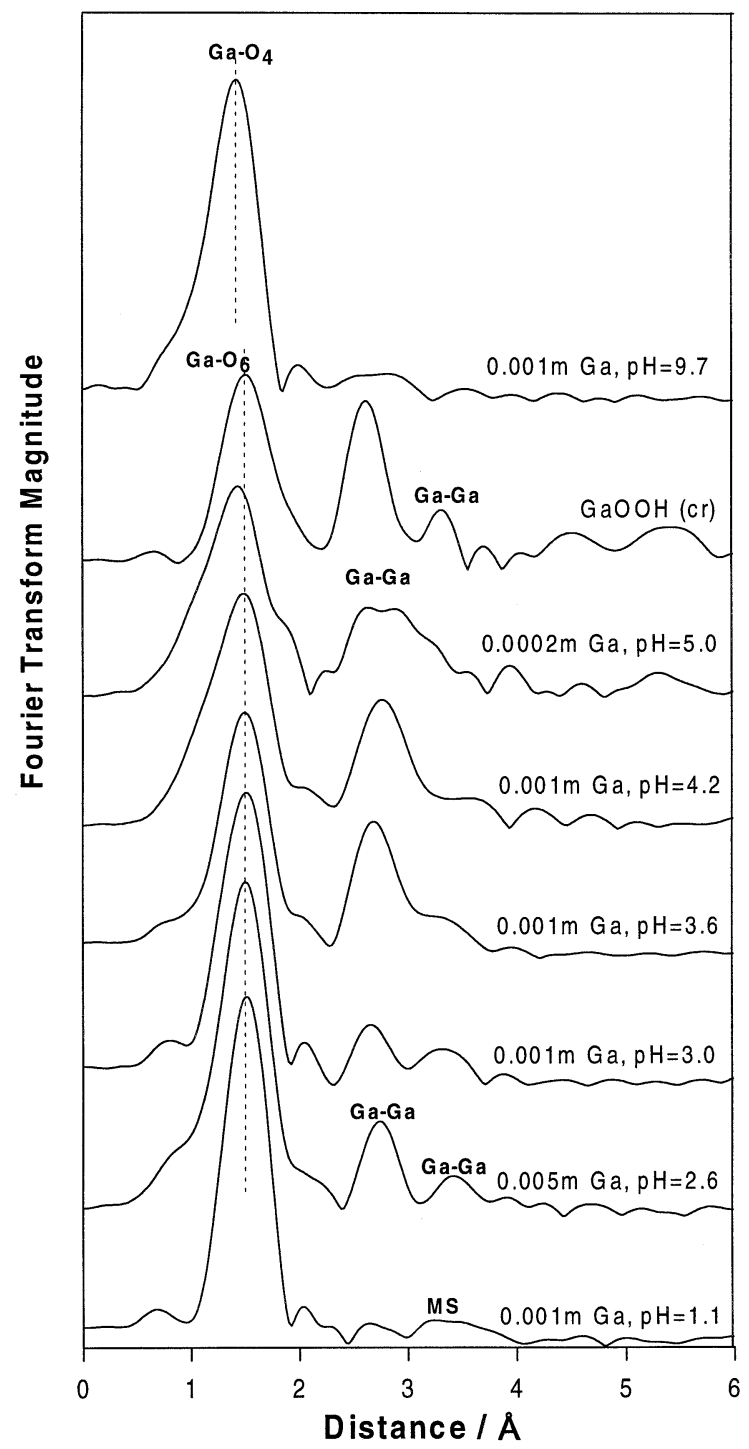

(b)

Fig. 4. $k^{2}$-weighted EXAFS spectra at Ga- $K$ edge of selected $\mathrm{Si}$-free Ga nitrate solutions as a function of $\mathrm{pH}$, and $\alpha$-GaOOH solid (a), and their corresponding Fourier transforms (not corrected for phase shift) (b). The vertical lines on (a) indicate the appearance of new contributions with increasing $\mathrm{pH}$, which correspond to $\mathrm{Ga}-\mathrm{O}-\mathrm{Ga}$ bonds in the polymerized Ga hydroxide complexes. The vertical lines on (b) denote Ga tetrahedral (at basic $\mathrm{pH}$ ) and octahedral coordination (at acid $\mathrm{pH}$ and $\alpha-\mathrm{GaOOH})$.

first shell were found to be negligible when fitting the second and third $\mathrm{Ga}$ atomic shells.

\section{NMR RESULTS}

\subsection{Acid Solutions}

${ }^{71} \mathrm{Ga}$ NMR spectra of $\mathrm{Ga}\left(\mathrm{NO}_{3}\right)_{3}$ aqueous solutions $(0.05 \leq$ $\left.m_{\mathrm{Ga}} \leq 0.24\right)$ obtained at different selected $\mathrm{pH}$ (different degrees of $\mathrm{Ga}^{3+}$ hydrolysis) in the presence or not of aqueous silica are presented in Fig. 1. In strongly acid silica-free solutions ( $\mathrm{pH} \sim 1.5$ ), a single narrow peak (half height width, $W_{1 / 2 H}=110 \mathrm{~Hz}$ ) corresponding to octahedral gallium
$\left[\mathrm{Ga}\left(\mathrm{H}_{2} \mathrm{O}\right)_{6}\right]^{3+}$ is observed at $0 \mathrm{ppm}$. As $\mathrm{pH}$ increases and hydrolysis progresses, the octahedral gallium peak broadens markedly (from $100 \mathrm{~Hz}$ at $\mathrm{pH}=1.5$ to $1500 \mathrm{~Hz}$ at $\mathrm{pH}=3.3$ ) while a small broad peak $(\sim 1300-1600 \mathrm{~Hz})$ located at $\sim 174$ ppm appears. The peak at $174 \mathrm{ppm}$ corresponds to gallium atoms in a distorted tetrahedral environment and has been assigned to the central gallium atom surrounded by 12 edgelinked $\mathrm{Ga}$ octahedra of a $\left[\mathrm{GaO}_{4} \mathrm{Ga}_{12}(\mathrm{OH})_{24}\left(\mathrm{H}_{2} \mathrm{O}\right)_{12}\right]^{7+}\left(\mathrm{Ga}_{13}\right)$ polycation analogous to $\mathrm{Al}_{13}$ (Johanson, 1962a, 1962b; Bradley et al., 1990a, 1990b; Michot et al., 2000). It should be emphasized that if this peak is much broader than that of tetrahedral 


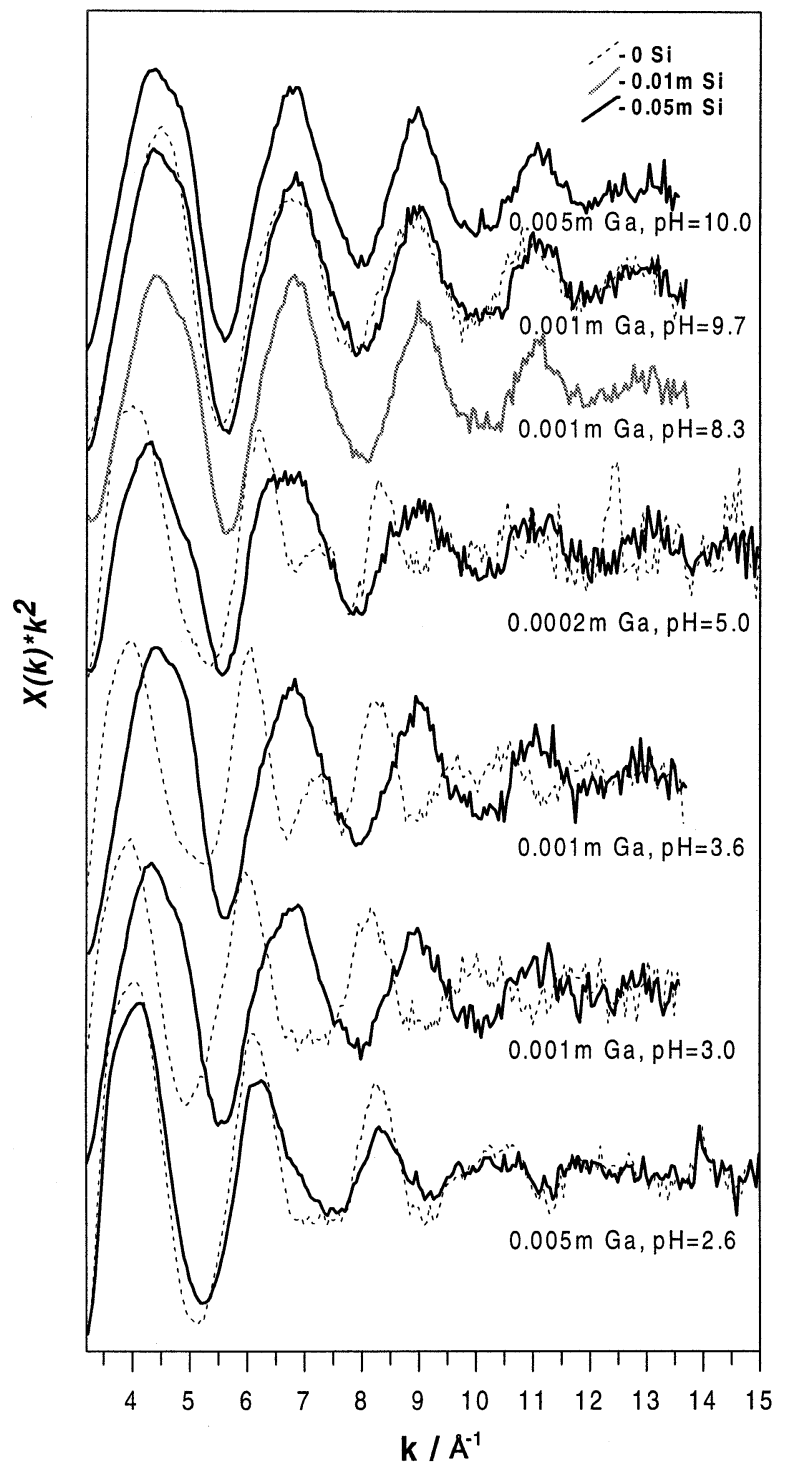

(a)

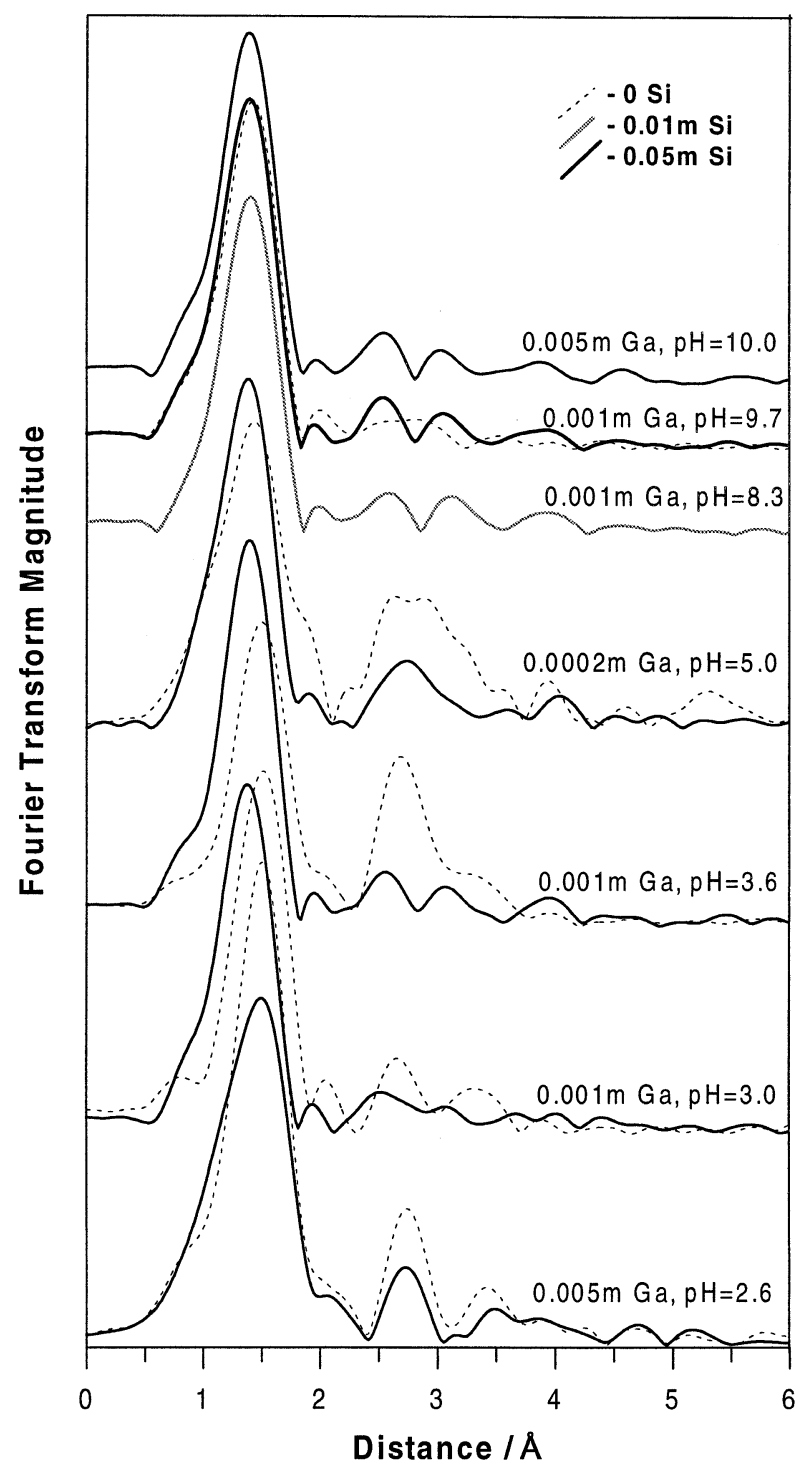

(b)

Fig. 5. $k^{2}$-weighted EXAFS spectra at Ga- $K$ edge of selected Ga nitrate solutions in the presence of aqueous silica at different $\mathrm{pH}$ (a), and their Fourier transforms (not corrected for phase shift) (b). The solid curves stand for Si-bearing solutions with indicated concentrations, but the dashed curves represent the spectra of the corresponding Si-free solutions at the same $\mathrm{pH}$ (see also Fig. 4).

$\mathrm{Al}$ in $\mathrm{Al}_{13}(\sim 20 \mathrm{~Hz})$ thus probably reflecting a more distorted environment in the case of tetrahedral $\mathrm{Ga}$, it appears at the exact position expected from the analogy with $\mathrm{Al}_{13}\left(v\left[\mathrm{Ga}_{\text {tetra }}\right] /\right.$ $\left.v\left[\mathrm{Ga}(\mathrm{OH})_{4}^{-}\right]=v\left[\mathrm{Al}_{\text {tetra }}\right] / v\left[\mathrm{Al}(\mathrm{OH})_{4}^{-}\right]=0.78\right)$. The broadening of the octahedral Ga peak at $0 \mathrm{ppm}$ reflects both the presence of Ga monomeric and polymeric hydroxide complexes and the formation of the $\mathrm{Ga}_{13}$ polycation. From the relative area of the peaks at 0 and $174 \mathrm{ppm}\left(S_{0} / S_{174} \sim 15-10\right)$ and that of the peak at $222 \mathrm{ppm}$ for the $\mathrm{Ga}(\mathrm{OH})_{4}^{-}$standard solution of known concentration, it can be inferred that the $\mathrm{Ga}_{13}$ polycation is largely dominant $(>60 \%)$ at $2.5<\mathrm{pH}<3.0$. At higher $\mathrm{pH}$, prior to Ga hydroxides precipitation, the ratio $S_{0} / S_{174}$ decreases markedly $\left(S_{0} / S_{174} \sim 1.6\right.$ at $\left.\mathrm{pH}=3.3\right)$ which can reflect the hydrolysis of $\mathrm{Ga}_{13}$ (i.e., replacement of some of the 12 water molecules by hydroxyl groups) and the subsequent condensation of $\mathrm{Ga}_{13}$ species leading to the formation of larger polycations (i.e., " $\mathrm{Ga}_{26}$ " or " $\mathrm{Ga}_{40}$ ", Baes and Mesmer, 1976) accommodating $\mathrm{Ga}$ atoms in both tetrahedral and octahedral coordination (see also XAFS results below). It should be noted that above $\mathrm{pH} 2.5$, as hydrolysis progresses, the surface area of the peak at $174 \mathrm{ppm}$ (compared to that of the $\mathrm{Ga}(\mathrm{OH})_{4}^{-}$standard solution) remains contant whereas that of the $0 \mathrm{ppm}$ peak considerably decreases, so that only $\sim 33 \%$ of the Ga initially present in solution could be detected. This suggests that the 


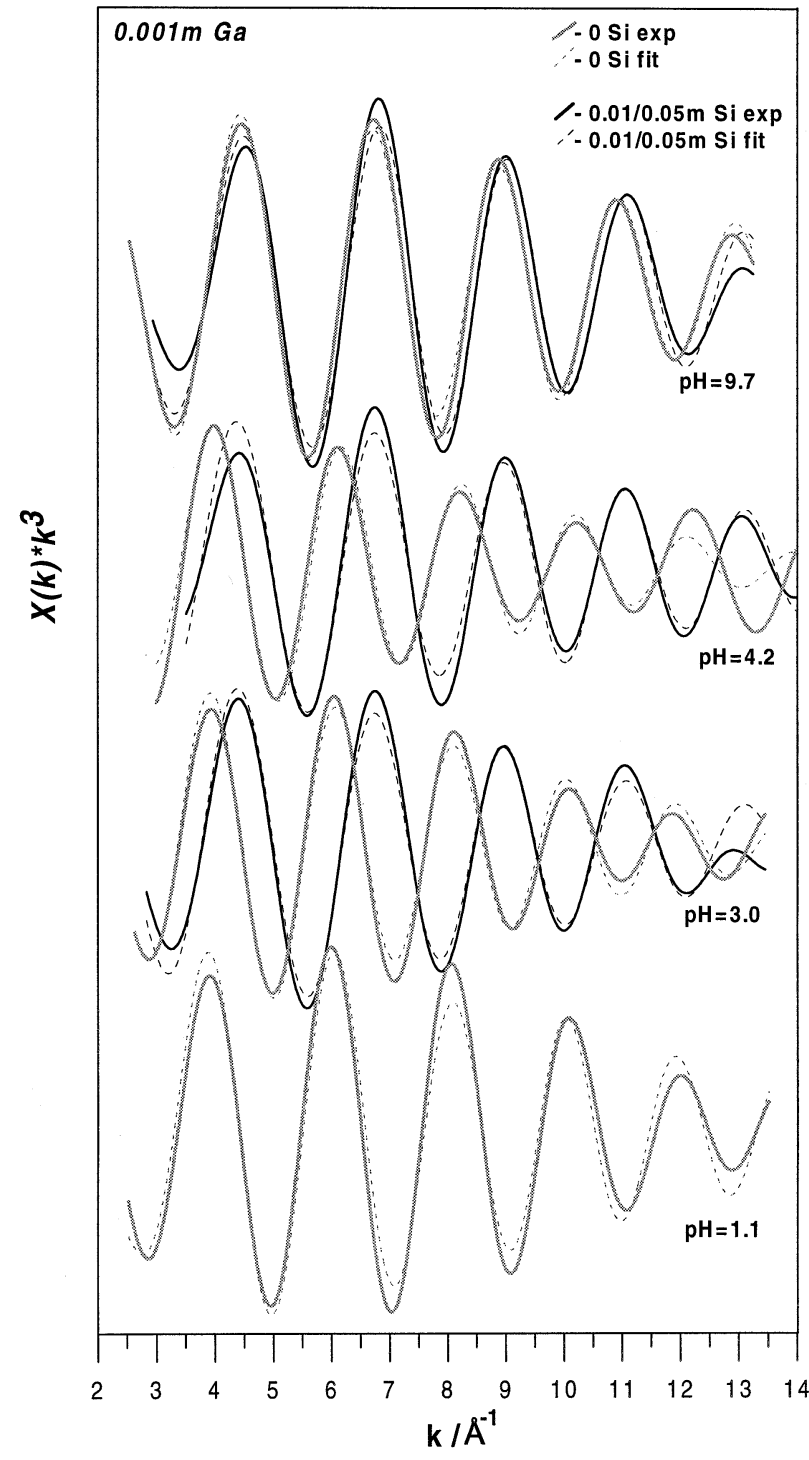

Fig. 6. EXAFS spectra of the first Ga atomic shell of selected 0.001 molal $\mathrm{Ga}$ nitrate solutions at indicated $\mathrm{pH}$ and $\mathrm{Si}$ concentration (solid lines) and their least-square fits (dashed lines). Significant amplitude and phase shifts between acid Si-free and Si-bearing solutions are apparent in this figure. This demonstrates that Ga changes its first shell coordination from 6 to 4 when complexing with silica in acid solutions (see text for details).

octahedral Ga sites in the newly formed polymers could be strongly disordered which attenuates the ${ }^{[6]} \mathrm{Ga}$ signal; and the tetrahedral Ga sites are likely to have a similar geometry as for the central ${ }^{[4]} \mathrm{Ga}$ in $\mathrm{Ga}_{13}$. At the same time, careful visual inspection of solutions, and $\mathrm{Ga}$ and $\mathrm{pH}$ analyses did not allow to detect any precipitation during the NMR measurements.

In silica bearing solutions (e.g., $m_{\mathrm{Ga}}=0.1, m_{\mathrm{SiO} 2 \text { (aq) }}=0.05$, $\mathrm{pH}=2.9$ ), the octahedral peak broadening considerably reduces $\left(W_{1 / 2 H}=690 \mathrm{~Hz}\right)$ whereas the tetrahedral Ga peak at 174 ppm disappears (Fig. 1). This suggests the formation of aqueous gallium-silica complexes with Ga in sixfold coordination which considerably slow down Ga hydrolysis and prevent the formation of $\mathrm{Ga}_{13}$.

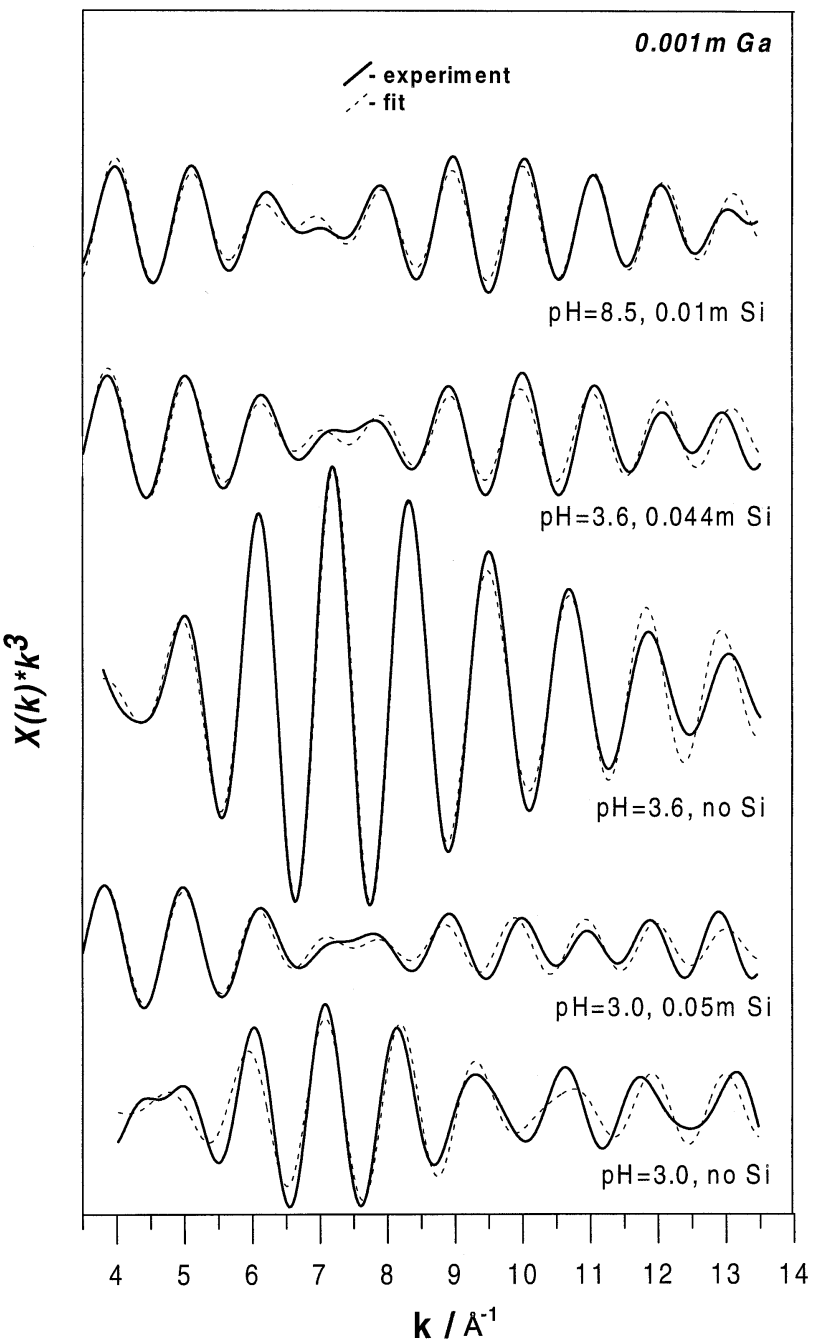

Fig. 7. EXAFS spectra of the second and third Ga atomic shells of selected 0.001 molal Ga solutions at indicated $\mathrm{pH}$ and $\mathrm{Si}$ concentration (solid lines), and their least-square fits (dashed lines). It can be seen that the amplitude of $\mathrm{Ga}$ beyond-the-first atomic shells is significantly suppressed in the presence of silica, which is also accompanied by distinct phase shifts. This demonstrates that the heavy Ga backscatterers in the polymerized complexes at acid $\mathrm{pH}$ are replaced by lighter silicon backscatterers in the presence of aqueous silica (see the text for details and Table 2 for fitted structural parameters).

\subsection{Alkaline Solutions}

In silica-free solutions $\left(m_{\mathrm{Ga}}=0.05, m_{\mathrm{SiO} 2(\mathrm{aq})}=0, \mathrm{pH}=\right.$ 12.7), a single narrow peak ( $W_{1 / 2 \mathrm{H}}=90 \mathrm{~Hz}$ ) corresponding to the tetrahedral gallate complex $\left(\mathrm{Ga}(\mathrm{OH})_{4}^{-}\right)$is observed at 222 ppm (Fig. 2). In the presence of aqueous silica $\left(m_{\mathrm{Ga}}=0.03\right.$, $\left.m_{\mathrm{SiO}_{2} \text { (aq) }}=0.1, \mathrm{pH}=11.7\right)$, this peaks broadens $\left(W_{1 / 2 H}=410\right.$ $\mathrm{Hz})$, and another very broad feature $\left(W_{1 / 2 H}=2450 \mathrm{~Hz}\right)$ is observed at $\sim 195 \mathrm{ppm}$. The broadening of the $222 \mathrm{ppm}$ peak is a consequence of the exchange of Ga atoms between monomeric gallate and gallosilicate anions (Mortlock et al., 1992). Following Mortlock et al. (1992) and by analogy with the results of ${ }^{27} \mathrm{Al}$ NMR investigation of alkaline aluminosilicate solutions (Pokrovski et al., 1998), the signal at 195 ppm can be 


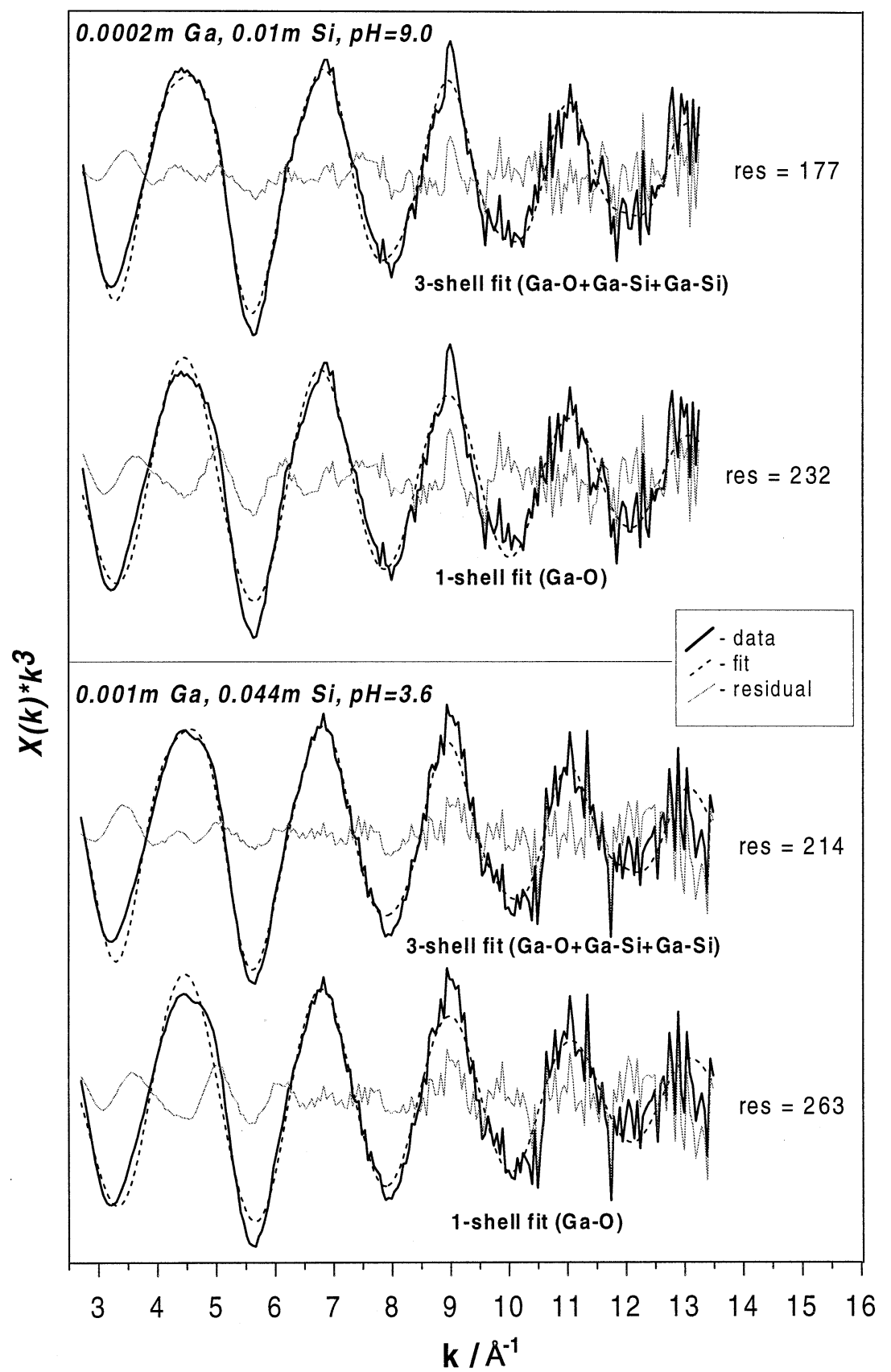

Fig. 8. Example of least-square fits of raw $k^{3}$-weighted EXAFS spectra for selected Si-bearing solutions. Fits were performed with either a single first $\mathrm{Ga}-\mathrm{O}$ shell or first $\mathrm{Ga}-\mathrm{O}$ shell plus two outer $\mathrm{Ga}-\mathrm{Si}$ shells, with parameters $(R, N$, DW) close to those reported in Tables 1 and 2. It can be seen that adding two Ga-Si contributions significantly improves the fit quality, expressed as res $=\Sigma\left(Y_{\text {data }}^{2}-Y_{\text {fit }}^{2}\right)$, where $\left(Y_{\text {data }}^{2}-Y_{\text {fit }}^{2}\right)$ is the squared difference between experimental and fitted EXAFS absorption coefficient $\left(K^{3} \cdot X\right)$ of the raw EXAFS signal for each point (see also Sect. 4.3.2).

tentatively assigned to $\mathrm{Ga}$ atoms in gallosilicate anions with two or three siloxane linkages.

\section{XAFS RESULTS}

\subsection{XANES Analysis}

XANES spectra of $\mathrm{Ga}\left(\mathrm{NO}_{3}\right)_{3}$ alkaline solutions with and without aqueous silica (Fig. 3) exhibit similar shape and edge- crest positions $(10,378 \pm 0.3 \mathrm{eV})$ suggesting the same local structure around $\mathrm{Ga}$ in these systems. Available solubility, potentiometric and NMR studies have shown that Ga, like Al, is tetrahedrally surrounded by $4 \mathrm{OH}$ groups in alkaline media (Baes and Mesmer, 1976; Bradley et al., 1990a; Bénézeth et al., 1997), which is also confirmed by our NMR measurements (see Sect. 3 above). XANES spectra of silica-free Ga nitrate solutions at $\mathrm{pH}$ from 1 to 5 show shapes and edge-crest positions 
Table 1. Structural parameters of the first Ga atomic shell obtained from fitting Ga K-edge EXAFS spectra of Ga nitrate solutions with and without aqueous silica.

\begin{tabular}{|c|c|c|c|c|c|c|c|}
\hline \multicolumn{3}{|c|}{ Solution composition } & \multirow[b]{2}{*}{ Atomic pair } & \multirow[b]{2}{*}{$R(\AA)$} & \multirow[b]{2}{*}{$N$ (atom) } & \multirow[b]{2}{*}{$\sigma^{2}$} & \multirow[b]{2}{*}{$\mathrm{chi}^{2}$} \\
\hline $\mathrm{pH}$ & $\begin{array}{c}\mathrm{m} \mathrm{Ga} \\
\mathrm{mol} / \mathrm{kg}\end{array}$ & $\begin{array}{c}\mathrm{m} \mathrm{Si} \\
\mathrm{mol} / \mathrm{kg}\end{array}$ & & & & & \\
\hline 1.1 & 0.001 & 0 & $\mathrm{Ga}-\mathrm{O}$ & $1.95(0.01)$ & $6.0(0.5)$ & 0.005 & 1.50 \\
\hline 1.1 & 0.005 & 0 & $\mathrm{Ga}-\mathrm{O}$ & $1.948(0.005)$ & $5.9(0.2)$ & 0.005 & 0.54 \\
\hline 2.6 & 0.005 & 0 & $\mathrm{Ga}-\mathrm{O}$ & $1.940(0.005)$ & $6.0(0.4)$ & 0.006 & 0.47 \\
\hline 3.0 & 0.001 & 0 & $\mathrm{Ga}-\mathrm{O}$ & $1.96(0.01)$ & $5.5(0.3)$ & 0.006 & 1.21 \\
\hline 3.6 & 0.001 & 0 & $\mathrm{Ga}-\mathrm{O}$ & $1.95(0.01)$ & $5.2(0.5)$ & 0.007 & 1.10 \\
\hline 4.2 & 0.001 & 0 & $\mathrm{Ga}-\mathrm{O}$ & $1.94(0.02)$ & $5.7(0.3)$ & 0.008 & 0.90 \\
\hline 5.0 & 0.0002 & 0 & $\mathrm{Ga}-\mathrm{O}$ & $1.88(0.03)$ & $5.6(0.3)$ & 0.009 & 1.07 \\
\hline 9.0 & 0.0002 & 0 & $\mathrm{Ga}-\mathrm{O}$ & $1.83(0.01)$ & $4.0(0.5)$ & 0.004 & 1.62 \\
\hline 9.7 & 0.001 & 0 & $\mathrm{Ga}-\mathrm{O}$ & $1.830(0.005)$ & $4.0(0.3)$ & 0.0035 & 0.89 \\
\hline 9.6 & 0.005 & 0 & $\mathrm{Ga}-\mathrm{O}$ & $1.830(0.005)$ & $4.0(0.5)$ & 0.005 & 1.10 \\
\hline 9.7 & 0.005 & 0 & $\mathrm{Ga}-\mathrm{O}$ & $1.840(0.005)$ & $3.8(0.2)$ & 0.0035 & 1.50 \\
\hline \multirow[t]{2}{*}{2.7} & \multirow[t]{2}{*}{0.005} & \multirow[t]{2}{*}{0.056} & $\mathrm{Ga}-\mathrm{O} 1$ & $1.940(0.003)$ & $5.3(0.4)$ & 0.007 & \\
\hline & & & $\mathrm{Ga}-\mathrm{O} 2$ & $1.81(0.01)$ & $1.2(0.2)$ & 0.006 & 0.60 \\
\hline 2.7 & 0.001 & 0.094 & $\mathrm{Ga}-\mathrm{O}$ & $1.810(0.005)$ & $3.5(0.5)$ & 0.004 & 1.06 \\
\hline 3.0 & 0.001 & 0.05 & $\mathrm{Ga}-\mathrm{O}$ & $1.812(0.002)$ & $3.9(0.2)$ & 0.007 & 0.73 \\
\hline 3.6 & 0.001 & 0.044 & $\mathrm{Ga}-\mathrm{O}$ & $1.810(0.005)$ & $4.0(0.2)$ & 0.004 & 0.70 \\
\hline 4.2 & 0.001 & 0.05 & $\mathrm{Ga}-\mathrm{O}$ & $1.808(0.005)$ & $3.7(0.5)$ & 0.004 & 1.25 \\
\hline 5.0 & 0.0002 & 0.05 & $\mathrm{Ga}-\mathrm{O}$ & $1.81(0.01)$ & $3.2(0.3)$ & 0.004 & 0.98 \\
\hline 8.2 gel & 0.005 & 0.06 & $\mathrm{Ga}-\mathrm{O}$ & $1.820(0.005)$ & $4.0(0.3)$ & 0.004 & 1.70 \\
\hline 8.3 & 0.001 & 0.011 & $\mathrm{Ga}-\mathrm{O}$ & $1.820(0.002)$ & $3.9(0.2)$ & 0.004 & 1.40 \\
\hline 8.5 & 0.001 & 0.011 & $\mathrm{Ga}-\mathrm{O}$ & $1.810(0.005)$ & $3.8(0.3)$ & 0.003 & 2.00 \\
\hline 9.0 & 0.0002 & 0.01 & $\mathrm{Ga}-\mathrm{O}$ & $1.810(0.005)$ & $4.1(0.2)$ & 0.004 & 0.70 \\
\hline 9.7 & 0.001 & 0.01 & $\mathrm{Ga}-\mathrm{O}$ & $1.805(0.005)$ & $3.8(0.3)$ & 0.003 & 1.93 \\
\hline 9.7 & 0.001 & 0.051 & $\mathrm{Ga}-\mathrm{O}$ & $1.807(0.002)$ & $4.2(0.2)$ & 0.004 & 1.50 \\
\hline 9.7 & 0.005 & 0.05 & $\mathrm{Ga}-\mathrm{O}$ & $1.810(0.005)$ & $3.8(0.2)$ & 0.003 & 0.90 \\
\hline 10.0 & 0.005 & 0.048 & $\mathrm{Ga}-\mathrm{O}$ & $1.812(0.005)$ & $4.0(0.2)$ & 0.0035 & 1.30 \\
\hline 10.9 & 0.001 & 0.01 & $\mathrm{Ga}-\mathrm{O}$ & $1.84(0.01)$ & $3.8(0.3)$ & 0.003 & 1.69 \\
\hline \multirow[t]{2}{*}{$\alpha-\mathrm{GaOOH}$} & & & $\mathrm{Ga}-\mathrm{O} 1$ & $1.92(0.01)$ & $2.5(0.5)$ & 0.003 & \\
\hline & & & $\mathrm{Ga}-\mathrm{O} 2$ & $2.05(0.02)$ & $3.0(0.5)$ & 0.003 & 0.70 \\
\hline
\end{tabular}

$R=$ Ga-neighbor mean distance, $N=$ Ga coordination number, $\sigma^{2}=$ squared Debye-Waller factor, chi ${ }^{2}=D /(F \times M) \times\left(Y_{\text {exp }}^{2}-Y_{\text {fit }}{ }^{2}\right.$, where $D=$ number of independent data, $F=$ degrees of freedom, $M=$ number of data points fitted, and $Y_{\text {exp }}^{2}-Y_{\text {fit }}^{2}=$ squared difference between experimental and fitted EXAFS absorption coefficient $\left(k^{3} \cdot X\right)$ of the filtered signal for each point (Press et al., 1986).

Values in parentheses represent average uncertainty for $R$ and $N$. Typical uncertainty for $\sigma^{2}$ is $\pm 0.0005 \AA^{2}$; gel $=$ the formation of a gel was observed in solution before measurements.

$(10,379.0-10,379.5 \mathrm{eV})$ similar to those of $\alpha-\mathrm{GaOOH}$. Since the first coordination shell of $\mathrm{Ga}$ in $\alpha$-GaOOH corresponds to six oxygens forming a distorted octahedron (Pye et al., 1977), aqueous $\mathrm{Ga}$ at acid $\mathrm{pH}$ is likely to have a similar environment. By contrast, in Ga-bearing solutions at pH from 2.7 to 5 in the presence of $0.04-0.1 \mathrm{~m} \mathrm{SiO}_{2}(a q)$, the shape and edge-crest position $(10,378.3 \mathrm{eV})$ are distinctly different, resembling those observed in the alkaline solutions. The shift of 1 to $2 \mathrm{eV}$ to the lower energies and the spectral shape are consistent with the change of Ga coordination from 6 to 4 in the presence of silica (Higby et al., 1988; Behrens et al., 1995).

\subsection{EXAFS Analysis of Silica-Free Solutions}

\subsubsection{First atomic shell}

Normalized $k^{2}$-weighted EXAFS spectra and their Fourier transforms of selected Si-free solutions at different $\mathrm{pH}$ are reported in Figs. 4a and 4b. In strongly acid solutions ( $p H=$ 1.1, $G a=0.001-0.005 \mathrm{~m}$ ), both EXAFS spectra and their FT exhibit a single contribution from a first shell of oxygens around Ga. The model of the back transformed signal arising from the first Ga shell (Fig. 6) gives $6 \pm 0.5$ oxygens with a mean $\mathrm{Ga}-\mathrm{O}$ distance of $1.95 \pm 0.01 \AA$. This is consistent with the presence of the hydrated $\mathrm{Ga}^{3+}$ cation, $\mathrm{Ga}\left(\mathrm{OH}_{2}\right)_{6}^{3+}$, in excellent agreement with previous LAXS (large angle X-ray scattering) and EXAFS studies on concentrated Ga solutions $\left(\mathrm{Ga}-\mathrm{O}_{6}=1.96 \AA\right.$, Lindqvist-Reis et al., 1998; $\mathrm{Ga}-\mathrm{O}_{6}=1.95$ $\AA$, Michot et al., 2000).

At $\mathrm{pH}$ from 2.6 to 4.2 , the first coordination sphere of $\mathrm{Ga}$ deviates slightly from a regular octahedron, as indicated by an increase of the DW factor (from 0.005 to 0.008 , see Table 1). The coordination and average $\mathrm{Ga}-\mathrm{O}$ distance remain the same within errors as for the strongly acid solutions $(R=1.94 \pm$ $0.02 \AA, N=5.5 \pm 0.5)$. At higher $p H(p H \geq 4.5)$, however, the $\mathrm{Ga}-\mathrm{O}$ average distance decreases to about $1.90 \AA$. This significant bond shortening is accompanied by an increase of DW factors (to $\sim 0.01$ ). The examination of the Fourier transform of three successive scans for a $2 \times 10^{-4} \mathrm{~m} \mathrm{Ga}$ solution at $\mathrm{pH} 5$ reveals significant changes in the form of both first and second Ga shells with time (Fig. 9). Inspite of the significant noise 
Table 2. Structural parameters of the second and third Ga atomic shells obtained from fitting Ga $K$-edge EXAFS spectra of Ga nitrate solutions with and without aqueous silica.

\begin{tabular}{|c|c|c|c|c|c|c|c|}
\hline \multicolumn{3}{|c|}{ Solution composition } & \multirow[b]{2}{*}{ Atomic pair } & \multirow[b]{2}{*}{$R(\AA)$} & \multirow[b]{2}{*}{$N$ (atom) } & \multirow[b]{2}{*}{$\sigma^{2}$} & \multirow[b]{2}{*}{$\mathrm{chi}^{2}$} \\
\hline $\mathrm{pH}$ & $\begin{array}{c}\mathrm{m} \mathrm{Ga} \\
\mathrm{mol} / \mathrm{kg}\end{array}$ & $\begin{array}{c}\mathrm{m} \mathrm{Si} \\
\mathrm{mol} / \mathrm{kg}\end{array}$ & & & & & \\
\hline 1.1 & 0.001 & 0 & n.d. & & & & \\
\hline 1.1 & 0.005 & 0 & n.d. & & & & \\
\hline \multirow{2}{*}{$\begin{array}{l}1.1 \\
2.6\end{array}$} & 0.005 & 0 & $\mathrm{Ga}-\mathrm{Ga} 1$ & 3.03 & 1.4 & 0.005 & 0.95 \\
\hline & & & $\mathrm{Ga}-\mathrm{Ga} 2$ & 3.52 & 0.6 & 0.009 & \\
\hline \multirow[t]{2}{*}{3.0} & 0.001 & 0 & Ga-Ga1 & 3.04 & 1.1 & 0.006 & 0.70 \\
\hline & & & $\mathrm{Ga}-\mathrm{Ga} 2$ & 3.47 & 0.6 & 0.004 & \\
\hline \multirow[t]{2}{*}{3.6} & 0.001 & 0 & $\mathrm{Ga}-\mathrm{Ga} 1$ & 3.04 & 3.0 & 0.007 & 0.42 \\
\hline & & & $\mathrm{Ga}-\mathrm{Ga} 2$ & 3.51 & 1.5 & 0.009 & \\
\hline \multirow[t]{2}{*}{4.2} & 0.001 & 0 & $\mathrm{Ga}-\mathrm{Ga} 1$ & 3.05 & 2.8 & 0.007 & 0.90 \\
\hline & & & $\mathrm{Ga}-\mathrm{Ga} 2$ & 3.49 & 1.8 & 0.005 & \\
\hline \multirow[t]{2}{*}{5.0} & 0.0002 & 0 & $\mathrm{Ga}-\mathrm{Ga} 1$ & 3.01 & 1.5 & 0.005 & 0.47 \\
\hline & & & $\mathrm{Ga}-\mathrm{Ga} 2$ & 3.44 & 0.9 & 0.009 & \\
\hline 9.0 & 0.0002 & 0 & n.d. & & & & \\
\hline 9.6 & 0.005 & 0 & n.d. & & & & \\
\hline 9.7 & 0.005 & 0 & n.d. & & & & \\
\hline \multirow[t]{2}{*}{2.7} & 0.005 & 0.056 & $\mathrm{Ga}-\mathrm{Ga}$ & 3.03 & 0.5 & 0.004 & 0.42 \\
\hline & & & $\mathrm{Ga}-\mathrm{Si}$ & 3.17 & 1.7 & 0.010 & \\
\hline 2.7 & 0.001 & 0.094 & $\mathrm{Ga}-\mathrm{Si}$ & 3.21 & 1.7 & 0.007 & 0.30 \\
\hline \multirow[t]{2}{*}{3.0} & 0.001 & 0.05 & $\mathrm{Ga}-\mathrm{Si} 1$ & 3.20 & 2.0 & 0.008 & 0.29 \\
\hline & & & $\mathrm{Ga}-\mathrm{Si} 2$ & 3.41 & 2.0 & 0.008 & \\
\hline \multirow[t]{2}{*}{3.6} & 0.001 & 0.044 & Ga-Si1 & 3.17 & 2.0 & 0.007 & 0.42 \\
\hline & & & $\mathrm{Ga}-\mathrm{Si} 2$ & 3.39 & 2.4 & 0.006 & \\
\hline \multirow[t]{2}{*}{4.2} & 0.001 & 0.05 & Ga-Si1 & 3.22 & 2.5 & 0.008 & 0.20 \\
\hline & & & $\mathrm{Ga}-\mathrm{Si} 2$ & 3.42 & 1.7 & 0.005 & \\
\hline 5.0 & 0.0002 & 0.05 & $\mathrm{Ga}-\mathrm{Si}$ & 3.20 & 2.5 & 0.009 & 0.33 \\
\hline 8.2 & 0.005 & 0.06 & n.d. & & & & \\
\hline \multirow[t]{2}{*}{8.3} & 0.001 & 0.011 & $\mathrm{Ga}-\mathrm{Si} 1$ & 3.20 & 2.0 & 0.009 & 0.43 \\
\hline & & & $\mathrm{Ga}-\mathrm{Si} 2$ & 3.43 & 2.0 & 0.009 & \\
\hline \multirow[t]{2}{*}{8.5} & 0.001 & 0.011 & Ga-Sil & 3.16 & 2.4 & 0.008 & 0.26 \\
\hline & & & $\mathrm{Ga}-\mathrm{Si} 2$ & 3.40 & 2.0 & 0.006 & \\
\hline \multirow[t]{2}{*}{9.0} & 0.0002 & 0.01 & Ga-Si1 & 3.17 & 2.8 & 0.009 & 0.52 \\
\hline & & & $\mathrm{Ga}-\mathrm{Si} 2$ & 3.39 & 2.5 & 0.006 & \\
\hline \multirow[t]{2}{*}{9.7} & 0.001 & 0.01 & Ga-Si1 & 3.12 & 2.0 & 0.007 & 0.39 \\
\hline & & & $\mathrm{Ga}-\mathrm{Si} 2$ & 3.36 & 1.9 & 0.008 & \\
\hline \multirow[t]{2}{*}{9.7} & 0.001 & 0.051 & $\mathrm{Ga}-\mathrm{Si} 1$ & 3.11 & 2.0 & 0.007 & 0.44 \\
\hline & & & $\mathrm{Ga}-\mathrm{Si} 2$ & 3.35 & 2.0 & 0.007 & \\
\hline 9.7 & 0.005 & 0.05 & n.d. & & & & \\
\hline \multirow[t]{2}{*}{10.0} & 0.005 & 0.048 & Ga-Si1 & 3.12 & 2.1 & 0.006 & 0.29 \\
\hline & & & $\mathrm{Ga}-\mathrm{Si} 2$ & 3.35 & 2.5 & 0.009 & \\
\hline 10.9 & 0.001 & 0.01 & n.d. & & & & \\
\hline \multirow{3}{*}{$\alpha-\mathrm{GaOOH}$} & & & $\mathrm{Ga}-\mathrm{Ga} 1$ & 2.95 & 2 fix & 0.004 & \\
\hline & & & $\mathrm{Ga}-\mathrm{Ga} 2$ & 3.24 & 2 fix & 0.006 & 1.63 \\
\hline & & & $\mathrm{Ga}-\mathrm{Ga} 3$ & 3.41 & 4 fix & 0.009 & \\
\hline
\end{tabular}

$R=$ Ga-neighbor mean distance, $N=$ Ga coordination number, $\sigma^{2}=$ squared Debye-Waller factor, chi $^{2}=D /(F \times M) \times \Sigma\left(Y_{\text {exp }}^{2}-Y_{\text {fit }}^{2}\right)($ see footnote for Table 1). Typical uncertainties for the determination of $R, N$ and $\sigma^{2}$ are $\pm 0.02 \AA, \pm 0.5$ atom for Ga-Si pairs or \pm 0.3 atom for Ga-Ga pairs, and $\pm 0.003 \AA^{2}$, respectively. Fix = value was fixed during fitting; n.d. = second atomic shell was not detected.

affecting these spectra, a broadening of the FT peak corresponding to the Ga first coordination shell, accompanied by a shift to shorter Ga-O distances, can be observed in this figure. The mean first shell Ga-O distance derived from the third scan is $1.88 \pm 0.03 \AA$, which is significantly lower than the $\mathrm{Ga}-\mathrm{O}_{6}$ distance of first $\mathrm{Ga}$ shell in more acidic solutions $\left(R_{1} \sim 1.94 \pm\right.$ $0.03 \AA$ ) or the average $\mathrm{Ga}-\mathrm{O}$ distance in $\alpha-\mathrm{GaOOH}$ solid $(R \sim 1.98 \AA)$. Consequently, the shorter $\mathrm{Ga}-\mathrm{O}$ distance suggests the presence of $\mathrm{Ga}$ atoms in both sixfold $\left(R_{\mathrm{Ga}-\mathrm{O}_{6}} \sim 1.95 \AA\right)$ and fourfold coordination with oxygens $\left(R_{\mathrm{Ga}-\mathrm{O}_{4}} \sim 1.83 \AA\right.$, see below). However, the short $k$ range of this spectrum (from $\sim 3$ to $\sim 14 \AA^{-1}$ ) did not permit resolution of such a splitting, instead the least-square fit of the first $\mathrm{Ga}$ shell using two $\mathrm{Ga}-\mathrm{O}$ contributions converged in all cases to a single $\mathrm{Ga}-\mathrm{O}$ distance (Table 1).

The spectra of silica-free solutions at basic $p H$ exhibit a single contribution which corresponds to $\mathrm{Ga}$ first shell with four oxygen atoms and $\mathrm{Ga}-\mathrm{O}$ average distances of $1.83 \pm$ $0.005 \AA$ (Fig. 4, Table 1). This is consistent with the tetrahedral $\mathrm{Ga}(\mathrm{OH})_{4}^{-}$species which is dominant at $\mathrm{pH}>5$ in aqueous solution, similar to $\mathrm{Al}(\mathrm{OH})_{4}^{-}$(Baes and Mesmer, 1976; Bénézeth et al., 1997; Diakonov et al., 1997). The obtained Ga-O 


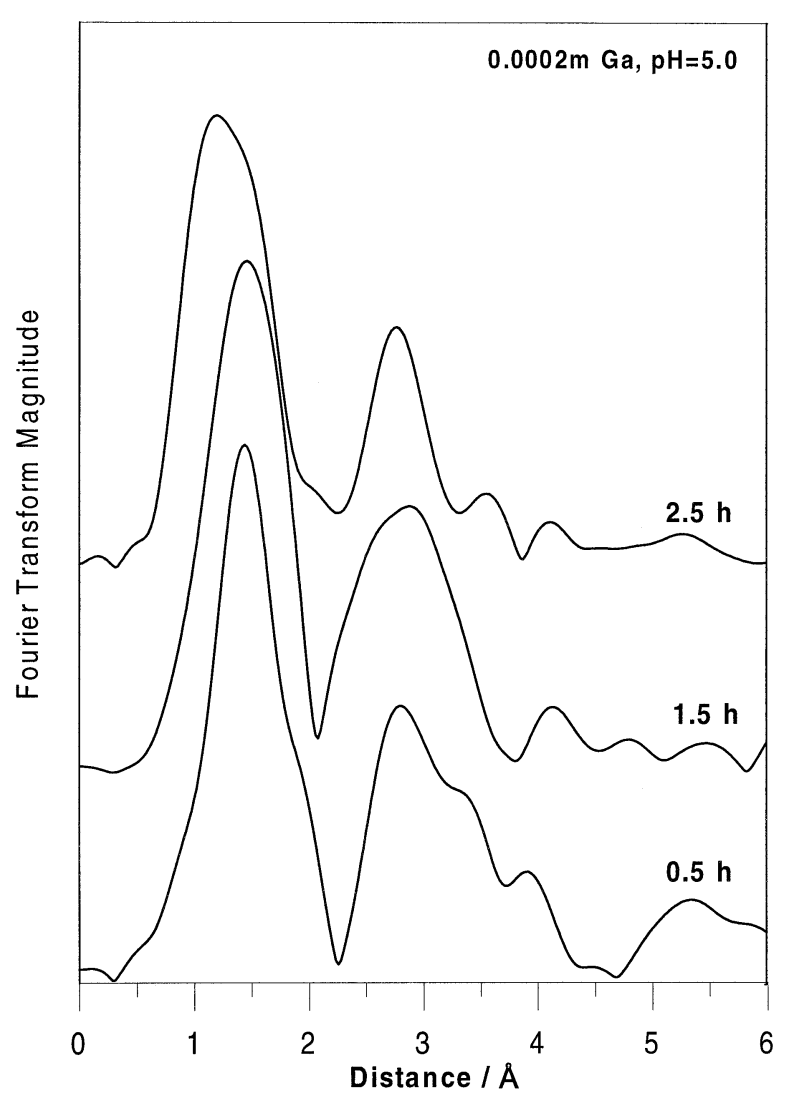

Fig. 9. Evolution of the FT of EXAFS spectra of three successive scans of a 0.0002 molal Ga nitrate solution at $\mathrm{pH}=5$. The numbers on the figure correspond to the time (in hours) elapsed between the solution preparation and spectra acquisition.

distances are typical for a tetrahedral environment, and in agreement with those found by EXAFS spectroscopy in highly concentrated sodium gallate solutions $(\mathrm{Ga}-\mathrm{O}=1.80 \AA, 0.5 \mathrm{~m}$ $\mathrm{Ga}$, Dooryhee et al., 1990), and those for tetrahedral Ga in the framework of Ga-bearing zeolites $(\mathrm{Ga}-\mathrm{O}=1.78-1.85 \AA$, Behrens et al., 1995; Fricke et al., 2000), alkali gallosilicate glasses $\left(\mathrm{Ga}-\mathrm{O}=1.83 \AA\right.$, Higby et al., 1988), and $\beta-\mathrm{Ga}_{2} \mathrm{O}_{3}$ (Ga-O = 1.83-1.86 ̊., Ahman et al., 1996).

\subsubsection{Second and third atomic shells}

At $\mathrm{pH}$ lower than 2, the minor feature observed at $3.5 \AA$ on the FT spectra (Fig. 4b, not corrected for phase shift) might correspond to multiple scattering paths within the symmetrical $\mathrm{GaO}_{6}$ octahedron (Lindqvist-Reis et al., 1998). At higher $p H$, this contribution vanishes, and another important second shell feature is observed, with its intensity growing with increasing $\mathrm{pH}$. This feature is similar to that of $\alpha-\mathrm{GaOOH}$, and corresponds to several $\mathrm{Ga}-\mathrm{Ga}$ pairs with distances ranging from 3.00 to $3.50 \AA$. The appearance of $\mathrm{Ga}-\mathrm{Ga}$ contributions clearly demonstrates the formation of Ga polymerized hydroxide complexes. The second shell feature was successfully fitted using two Ga-Ga subshells with distances of $3.01 \leq R_{1} \leq 3.04$ and $3.45 \leq R_{2} \leq 3.50 \AA$ (Table 2, Fig. 7). From the analogy with $\mathrm{Ga}$ oxy-hydroxide solids whose structures consist of $\mathrm{Ga}-\mathrm{O} /$ $(\mathrm{OH})_{6}$ octahedra sharing their faces $\left(R_{\mathrm{Ga}-\mathrm{Ga}}=2.84 \AA\right.$ in
$\alpha-\mathrm{Ga}_{2} \mathrm{O}_{3}$, Michot et al., 2000), edges $\left(R_{\mathrm{Ga}-\mathrm{Ga}}=2.95-3.25 \AA\right.$ in $\alpha-\mathrm{GaOOH}$ and $\beta-\mathrm{Ga}_{2} \mathrm{O}_{3}$, Pye et al., 1977; Ahman et al., 1996) and/or double corners $\left(R_{\mathrm{Ga}-\mathrm{Ga}}=3.40 \AA\right.$ in $\alpha-\mathrm{GaOOH}$, Pye et al., 1977), the Ga-Ga distances derived for the hydrolyzed solutions can be attributed to polymeric species with edge and double-corner sharing $\mathrm{Ga}-\mathrm{O}_{6}$ octahedra. These structures found in our dilute solutions are similar to those of $\mathrm{Ga}(\mathrm{III})$, $\mathrm{Fe}(\mathrm{III})$, and $\mathrm{Cr}(\mathrm{III})$ hydroxide polymeric species formed in concentrated solutions $(0.2-1.0 \mathrm{~mol})$ during the hydrolysis of nitrate or chloride salts of these metals (Michot et al., 2000; Combes et al., 1989; Bottero et al., 1994; Jolivet et al., 1994). Note that beyond-the-first Ga shells of all hydrolyzed solutions investigated in this study were reasonably fitted using two Ga-Ga contributions at $\sim 3.0$ and $\sim 3.5 \AA$, in accordance to the degree of freedom for our EXAFS spectra between 4 and 7 (Stern, 1993). The addition of a third Ga-Ga shell (for example, at $\sim 3.3$ or $3.9 \AA$ ) led to highly correlated and often unreasonable Debye-Waller factors and coordination numbers and decreased significantly the goodness-of-fit parameter. Consequently, taking into account the signal-to-noise ratio and $k$ range of the spectra of the dilute solutions investigated in this study, a two-shell model was kept throughout analysis of $\mathrm{Ga}$ hydrolysis in acid solutions.

At $2.5 \leq p H \leq 3$, the numbers of $\mathrm{Ga}$ edge-sharing and corner-sharing neighbors $\left(N_{\text {edge }}=1.2 \pm 0.2\right.$ and $N_{\text {corner }}=0.6$ \pm 0.3 , respectively) are independent of Ga concentration and close to those found by Michot et al. (2000) for concentrated $(\sim 0.3 \mathrm{~m}$ Ga nitrate) solutions at similar $\mathrm{pH}$. In the $\mathrm{pH}$ region 3.5-4.5, the Ga-Ga features are very similar (Fig. 4), and give $\mathrm{Ga}-\mathrm{Ga}$ distances and number of neighbors of $3.05 \pm 0.02,3.50$ $\pm 0.02 \AA$, and $2.9 \pm 0.2,1.7 \pm 0.2 \mathrm{Ga}$ atoms, respectively (see Table 2). Our NMR measurements at $\mathrm{pH} \geq 2.5$ in more concentrated Ga solutions $(0.05-0.3 \mathrm{~m})$ clearly show the formation of the $\mathrm{Ga}_{13}$ cation of Keggin-type structure, analogous to $\mathrm{Al}_{13}$. In this structure (Fig. 11), each of the $12 \mathrm{Ga}$ atoms in octahedral coordination "sees" three octahedral neighbors at $3.04 \AA$ linked by edges $\left(N_{\text {mean }}=12^{\text {oct }} \times 3 / 13=2.8\right)$ and one central tetrahedral Ga at $3.50 \AA\left(N_{\text {mean }}=\left(12^{\text {oct }} \times 1+1^{\text {tetr }} \times\right.\right.$ $12) / 13=1.85)$. Thus, the coordination numbers derived in this study strongly suggest that $\mathrm{Ga}_{13}$ is the dominant $\mathrm{Ga}$ species at these $\mathrm{pH}$ in our dilute solutions. Note that the presence of a single central tetrahedrally coordinated Ga cannot be detected directly from the analysis of the first $\mathrm{Ga}-\mathrm{O}$ shell: $N_{\text {mean(Ga-O) }}$ would be equal to $(12 \times 6+1 \times 4) / 13=5.85$ in the ideal case of $100 \%$ predominance of $\mathrm{Ga}_{13}$ in solution, which is in the limit of the uncertainties $(6 \pm 0.3)$ when determining $N_{\mathrm{Ga}-\mathrm{O}}$ (see above, and Table 1).

At higher $p H$ (5.0), the Ga-Ga average distances decrease slightly (3.01 and $3.44 \AA$ ) which could be attributed to the hydrolysis of the $\mathrm{Ga}_{13}$ cation and formation of precursors of $\alpha$-GaOOH $(\mathrm{Ga}-\mathrm{Ga}$ distances $=2.97,3.23$, and $3.40 \AA$, Pye et al., 1977), which rapidly precipitates at $\mathrm{pH}$ around 5 . Indeed, the EXAFS spectrum and its Fourier transform for a $2 \times 10^{-4}$ $\mathrm{m}$ Ga solution at $\mathrm{pH} 5$ exhibit additional second-shell contributions and a higher noise than the spectra at lower $\mathrm{pH}$ (Figs. $4 \mathrm{a}$ and $4 \mathrm{~b}$ ). This can be explained by the rapid kinetics of both transformation of $\mathrm{Ga}_{13}$ and formation of $\mathrm{Ga}(\mathrm{OH})_{3} / \mathrm{GaOOH}$ nuclei, which was faster than the time required for a single scan acquisition ( $\sim 50 \mathrm{~min}$ ). Like the first shell (see above), the second shell of Ga evolves significantly with time (Fig. 9). The 
hydrolysis of the $\mathrm{Ga}_{13}$ cation with increasing $\mathrm{pH}$ and before the precipitation of Ga hydroxides is likely to proceed through the formation of larger polymeric hydroxide complexes in which a part of Ga is tetracoordinated, as suggested from the analysis of the first shell (Sect. 4.2.1). Note, that our NMR spectroscopy measurements at higher $\mathrm{Ga}$ concentration $(\sim 0.1-0.2 \mathrm{~m})$ and $\mathrm{pH}>2.9$ (see above) also suggest the hydrolysis and polymerization of $\mathrm{Ga}_{13}$, and the presence of significant amount of tetracoordinated gallium in the new polycations formed.

\subsection{EXAFS Analysis of Silica-Bearing Solutions}

\subsubsection{First atomic shell}

In the presence of aqueous silica at basic $p H$, the first shell $\mathrm{Ga}-\mathrm{O}_{4}$ distances are distinctly lower (by 0.02 to $0.03 \AA$ ) than for their $\mathrm{Si}$-free analogs. This bond shortening can be explained by the replacement of free $\mathrm{OH}$ groups in the $\mathrm{Ga}(\mathrm{OH})_{4}^{-}$species by $-\mathrm{O}-$ bridges and formation of $\mathrm{Ga}-\mathrm{O}-\mathrm{Si}$ bonds.

In the presence of aqueous silica at acid $\mathrm{pH}(2.7 \leq \mathrm{pH} \leq$ 5.0) important changes occur in the first coordination shell of gallium. The examination of the EXAFS spectra of Si-bearing solutions reveals distinct amplitude changes and phase shifts in comparison to those for their $\mathrm{Si}$-free analogs (Figs. 4a and 5a). The first shell Ga-O contribution to the Fourier transform (Fig. $5 b$ ) is shifted to shorter distances, which is also manifested by a phase shift of its IFT (Fig. 6). The modeling of the first Ga coordination shell $(\mathrm{Ga}-\mathrm{O})$ revealed a change in the number of neighbors $(4 \pm 0.5)$ and $\mathrm{Ga}-\mathrm{O}$ distance $(1.81 \pm 0.01 \AA)$ in comparison to the acid solutions without silica (see above). These parameters are surprisingly close to those found for the first shell of $\mathrm{Ga}$ in basic solutions.

At more acid $\mathrm{pH}(\mathrm{pH} \sim 2.7)$ and moderate $\mathrm{Si} / \mathrm{Ga}$ ratios (Si/ $G a \sim 10$ ), Ga first shell atomic environment was found to be intermediate between those in the polymeric Ga hydroxide species and $\mathrm{Ga}$-silicate complexes at higher $\mathrm{pH}$ or $\mathrm{Si}$ concentrations. Two Ga-O distances were detected, corresponding to octahedral $\left(R_{1}=1.94 \AA\right)$ and tetrahedral $\left(R_{2}=1.81 \AA\right)$ environment (Table 1). The Ga-O coordination number corresponding to the shorter distance $\left(N_{2}=1.2\right)$ implies that about $20-25 \%$ of $\mathrm{Ga}$ is in tetrahedral configuration.

\subsubsection{Second and third atomic shells}

At basic $p H(p H \geq 8)$, two new distinct contributions (at $\sim 2.7$ and $\sim 3.1 \AA$, not corrected for phase shift) were detected beyond the first shell (Fig. 5b). Their intensities are independent of Ga concentration, but grow with increasing Si content and decreasing $\mathrm{pH}$ (Figs. 10a and 10b), thus suggesting that these contributions arise from silicon atoms in the second coordination shell of gallium. Analysis of this shell was performed using two Ga-Si sets of structural parameters. To diminish the strong correlations between number of neighbors $(N)$ and DW factors, the $\sigma^{2}$ values for both $\mathrm{Ga}-\mathrm{Si}$ shells were restricted during the fitting to the range $0.002-0.02$. These values are typically found at ambient temperature for metalsilicon second shell pairs in zeolites (e.g., Dooryhee et al., 1990) and metal-Si/As/Se pairs in the surface complexes formed during silicate/arsenate/selenate sorption on or coprecipitation with $\mathrm{Fe}$ and $\mathrm{Cr}$ hydroxides (e.g., Fendorf et al., 1994; Waychunas et al., 1993; Manceau and Charlet, 1994). The high uncertainties associated with the derived $N_{\mathrm{Ga}-\mathrm{Si}}$ values (Table 2) are due to the weak signal arising from the Ga-Si contributions. Nevetheless, this signal is significantly higher than the spectral noise as demonstrated by fits of raw total EXAFS spectra (Fig. 8). It can be seen in this figure that adding two $\mathrm{Ga}-\mathrm{Si}$ contributions to the fit of raw spectra of Si-bearing solutions considerably improves the fit quality. The influence of MS scattering paths within the $\mathrm{Ga}-\mathrm{O}_{4}$ tetrahedron and $\mathrm{Ga}-\mathrm{O}-$ $\mathrm{Si}(\mathrm{O} / \mathrm{OH})_{3}$ structures, and of the possible presence of the $\mathrm{N}\left(\mathrm{CH}_{3}\right)_{4}^{+}$cation in the outer coordination shell were also tested, but they were found not to contribute to the $\mathrm{Ga}-\mathrm{Si}$ signal within errors. Reasonable fits were obtained for two $\mathrm{Ga}-\mathrm{Si}$ contributions with $R_{2}=3.12-3.20 \AA, N_{2}=2.0 \pm 0.5$, and $R_{3}$ $=3.35-3.43 \AA, N_{3}=1.5 \pm 0.5$ (Figs. 7 and 8; Table 2). The first Ga-Si distance is in agreement with that derived by Dooryhee et al. (1990) for Ga-Si pairs in their EXAFS study of Ga-Si alkaline gels $\left(R_{\mathrm{Ga}-\mathrm{Si}}=3.11-3.14 \AA\right)$. These $\mathrm{Ga}-\mathrm{Si}$ distances are very close to those found in crystalline sodium gallozeolites (Dooryhee et al., 1990; Nenoff et al., 1994) implying a similar Ga atomic environment in zeolites and their precursors formed from concentrated $\mathrm{Ga}-\mathrm{Si}$ alkaline solutions. The second $\mathrm{Ga}-\mathrm{Si}$ distance $\left(R_{3}=3.35-3.43 \AA\right)$ is close to those found by EXAFS spectroscopy in hydrothermally synthesized pentasil silicates ( $\mathrm{Ga}-\mathrm{Si}=3.45-3.50 \AA$, Okabe et al., 1991). The existence of two different $\mathrm{Ga}-\mathrm{Si}$ distances is likely to imply formation of two different types of aqueous complexes (see below).

At moderately acid $p H(2.7 \leq p H \leq 5.0)$, the Ga-Ga features observed in the second shell of the $\mathrm{SiO}_{2}$-free hydrolyzed $\mathrm{Ga}$ solutions, disappear in the presence of aqueous silica (Figs. 5a and 5 b). Instead, two new weak features appear at $\sim 2.7$ and $\sim 3.1 \AA$ (not corrected for phase shift), which closely resemble those observed in the $\mathrm{Ga}-\mathrm{Si}$ basic solutions, thus indicating the presence of analogous $\mathrm{Ga}-\mathrm{O}-\mathrm{Si}$ bonds. The modeling of these features was performed using one or two $\mathrm{Ga}-\mathrm{Si}$ contributions in the manner similar to that for the basic Si-bearing solutions (see above and Figs. 7 and 8). For $0.05 \mathrm{~m} \mathrm{Si}, 0.001 \mathrm{~m} \mathrm{Ga}$ solutions at $\mathrm{pH} 3-4.5(\mathrm{Si} / \mathrm{Ga}=50)$, two $\mathrm{Ga}-\mathrm{Si}$ contributions were resolved with $R_{2}=3.20 \pm 0.03 \AA, N_{2}=2.0 \pm 0.5$, and $R_{3}=3.40 \pm 0.02 \AA, N_{3}=2 \pm 0.5$. By contrast, in solutions with the highest $\mathrm{Si} / \mathrm{Ga}$ mole ratio $(\mathrm{Si} / \mathrm{Ga}=100-250: 0.05 \mathrm{~m}$ $\mathrm{Si}-0.0002 \mathrm{~m} \mathrm{Ga}-\mathrm{pH}=5.0$, and $0.094 \mathrm{~m} \mathrm{Si}-0.001 \mathrm{~m} \mathrm{Ga}-\mathrm{pH}$ $=2.7$, see Table 2 ), only a single Ga-Si distance could be resolved $\left(R_{2} \sim 3.20 \AA\right)$. This is probably due to both the low $\mathrm{Ga}-\mathrm{Si}$ signal in our dilute samples, and high structural disorder of Ga sites which attenuates the EXAFS signal. The difficulty in resolving Ga structural environment beyond its first coordination shell by XAFS or NMR spectroscopy has also been demonstrated for $\mathrm{Ga}-\mathrm{Si}$ concentrated alkaline solutions, gels, glasses and even crystalline zeolites (Behrens et al., 1995; Mortlock et al., 1992).

At more acid $p H(p H \sim 2.7)$ and moderate Si/Ga ratios $(\mathrm{Si} / \mathrm{Ga}=10)$, the presence of both $\mathrm{Ga}-\mathrm{Ga}$ and $\mathrm{Ga}-\mathrm{Si}$ contributions could be detected beyond the first shell at $3.03 \AA$ and $3.17 \AA$, respectively (Table 2 ). The first distance corresponds to Ga octahedra linked by their edges as in Si-free Ga hydrolyzed solutions. Gallium-gallium number of neighbors is however significantly decreased $\left(N_{\text {edge }}=0.5\right)$ in comparison to that in the $\mathrm{Si}$-free solutions of the same $\mathrm{pH}\left(N_{\text {edge }}=1.4\right)$. No Ga-Ga distances at $3.5 \AA$ corresponding to double corner linkages were detected in the presence of Si. The Ga-Si distance of 3.17 


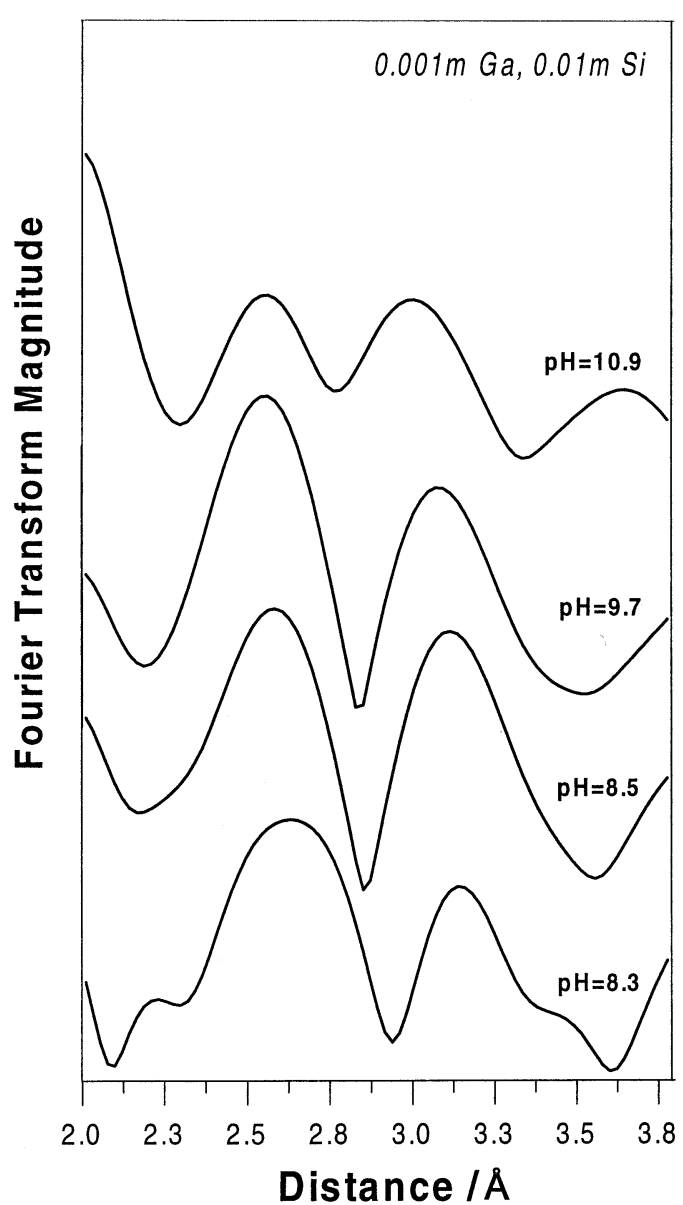

(a)

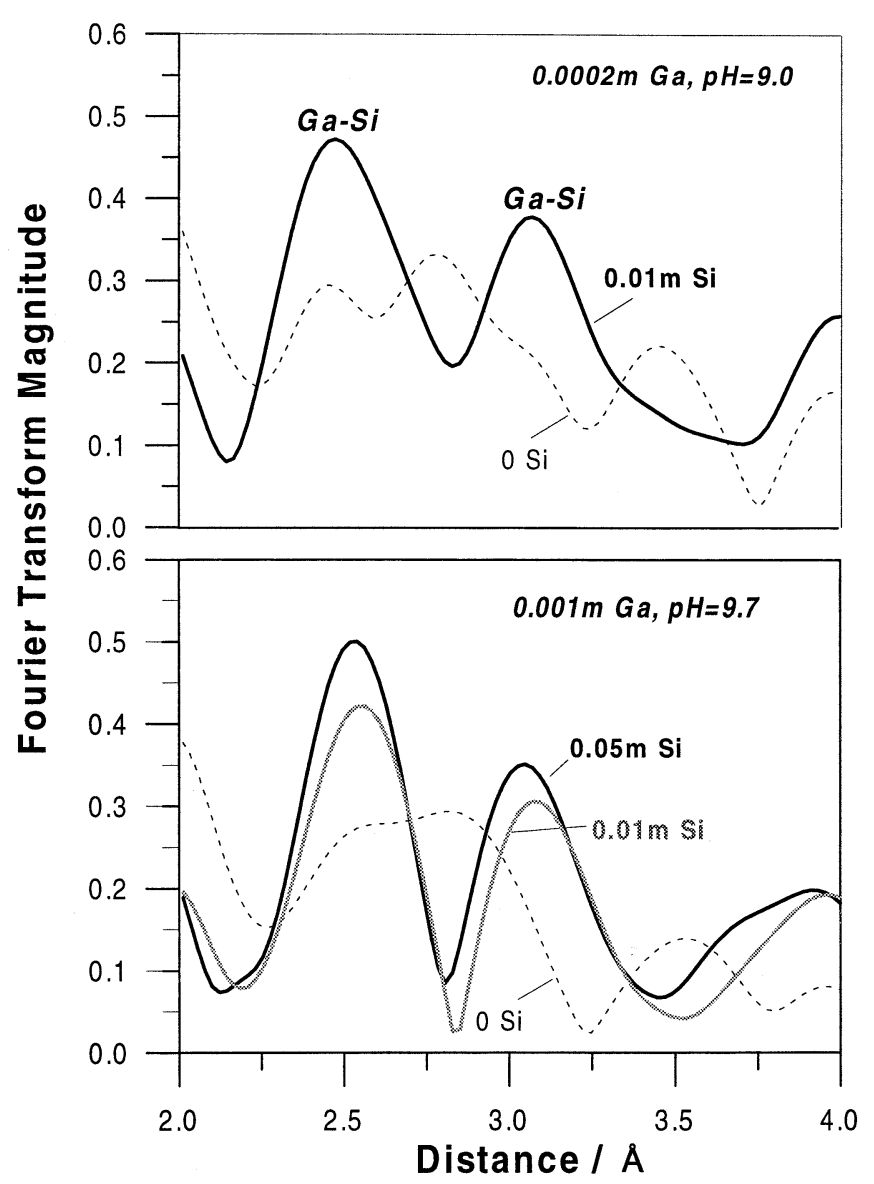

(b)

Fig. 10. Evolution of the second coordination shell of Ga shown as the Fourier transform (not corrected for phase shift) of the EXAFS spectra of basic Ga-Si solutions as a function of $\mathrm{pH}(\mathrm{a})$, and $\mathrm{Ga}$ and $\mathrm{Si}$ concentration (b).

$\AA$ is also very close to that found in tetrahedral Ga-Si complexes at higher $\mathrm{pH}$. As it was inferred from the analysis of the first shell (Sect. 4.3.1), about $20 \%$ of total $\mathrm{Ga}$ is present in tetrahedral coordination in this solution. If this ${ }^{[4]} \mathrm{Ga}$ were entirely complexed with four silicic acid ligands, the overall $\mathrm{Ga}-\mathrm{Si}$ coordination number would be only 0.8 . The experimental value is significantly higher $\left(N_{\mathrm{Ga}-\mathrm{Si}} \sim 1.7 \pm 0.5\right)$, implying that both ${ }^{[6]} \mathrm{Ga}-\mathrm{Si}$ and ${ }^{[4]} \mathrm{Ga}-\mathrm{Si}$ bonds are likely to be present in this solution.

\section{DISCUSSION}

\subsection{Gallium Hydrolysis}

The XAFS and NMR results of this study demonstrate that the $\mathrm{Ga}^{3+}$ cation rapidly hydrolyzes in dilute aqueous solution via formation of $\mathrm{Ga}$ oxy-hydroxide polynuclear species composed of $\mathrm{Ga}\left(\mathrm{O} / \mathrm{OH} / \mathrm{H}_{2} \mathrm{O}\right)_{6}$ octahedra linked together by their edges and double corners. In this respect, $\mathrm{Ga}$ hydrolysis is similar to that observed for $\mathrm{Fe}^{3+}, \mathrm{Cr}^{3+}$ and probably $\mathrm{Al}^{3+}$ cations (Baes and Mesmer, 1976; Jolivet et al., 1994). However, some differences in the stoichiometry and species distribution for these $\mathrm{M}^{3+}$ cations arise since the early stages of hydrolysis. At low $\mathrm{OH} / \mathrm{Ga}$ ratios $(\mathrm{pH} \leq 3.0)$ the coordination numbers derived in this study for the $\mathrm{Ga}-\mathrm{Ga}$ edge $\left(R_{\text {edge }}=\right.$ $3.04 \AA)$ and double corner $\left(R_{\text {corner }}=3.50 \AA\right)$ linkages $\left(N_{3.04} \AA\right.$ $\left.=1.1-1.4, N_{3.50} \AA=\sim 0.6\right)$ could imply either the formation of the $\mathrm{Ga}_{13}$ polycation (e.g., $30 \% \mathrm{Ga}_{13}+70 \%$ monomeric $\left.\mathrm{Ga}(\mathrm{OH})_{n}\right)$, or the presence of a mixture of smaller different polymers like edge and double-corner shearing di-, tri, or tetramers whose schematic structures are represented in Fig. 11. Analogous species were also proposed by Michot et al. (2000) for early stages of Ga hydrolysis in highly concentrated $(0.3 \mathrm{~m} \mathrm{Ga})$ solutions. Similar polycations were suggested as intermediate species leading to the formation of two types of edge-linked tetramers during the early stages of $\mathrm{Cr}^{3+}$ hydrolysis (Jolivet et al., 1994). Small polynuclear species of iron (III) are less stable than their Ga analogs: Fe edge-linked dimers and double-corner trimers rapidly form larger polymers with $\beta$-FeOOH-like structures (i.e., " $\mathrm{Fe}_{24}$ " polycation, Bottero et al., 1994).

For OH/Ga ratios higher than 2, the numbers of Ga neighbors and $\mathrm{Ga}-\mathrm{Ga}$ distances derived from our EXAFS analysis, together with the NMR signal arising from the $\mathrm{Ga}-\mathrm{O}_{4}$ tetrahedron, clearly demonstrate that the $\mathrm{Ga}_{13}$ cation of Keggin-type 


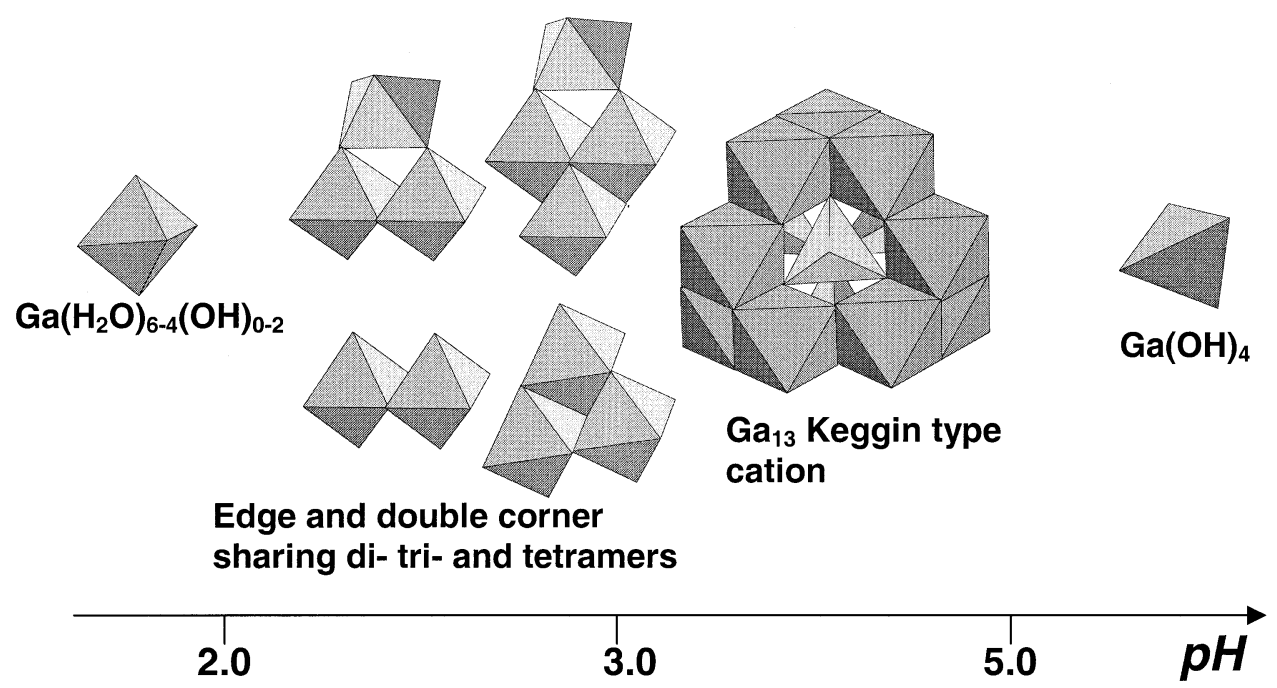

Fig. 11. Schematic structures of Ga hydroxide complexes formed as a function of $\mathrm{pH}$ in aqueous solution during $\mathrm{Ga}^{3+}$ hydrolysis.

structure is the dominant species in our solutions of low to moderate Ga concentration $\left(0.0002 \leq m_{\mathrm{Ga}} \leq 0.1\right)$. The $\mathrm{Ga}_{13}$ formation was also reported for more concentrated Ga nitrate and chloride solutions at similar hydrolysis ratios (Bradley et al., 1990a, 1990b; Michot et al., 2000).

At $\mathrm{pH}$ above 4.5, the $\mathrm{Ga}_{13}$ cation seems to transform into more disordered $\mathrm{GaOOH}-\mathrm{Ga}(\mathrm{OH})_{3}$ precursors (see Sect. 4.2.1) which is manifested by the decrease of $\mathrm{Ga}-\mathrm{Ga}$ number of neighbors and Ga-Ga distances (see Table 2, the $2 \times 10^{-4} \mathrm{Ga}$ solution at $\mathrm{pH} 5$ ). In this respect, the $\mathrm{Ga}_{13}$ polycation is less stable than its aluminum analog which could be isolated in crystalline state by precipitation of basic $\mathrm{Al}$ sulfates and selenates at $\mathrm{OH} / \mathrm{Ga}$ ratios higher than 2 (Johansson, 1962a, $1962 b)$. The rapid transformation of $\mathrm{Ga}_{13}$ observed in this study by EXAFS and NMR spectroscopy, respectively, at $\mathrm{pH}>4.5$ at low $\mathrm{Ga}$ concentrations $(<0.001 \mathrm{~m})$ and at $\mathrm{pH}>2.9$ in more concentrated solutions $(\geq 0.1 \mathrm{~m})$, is likely to proceed via the formation of less ordered bigger polymeric species having significant proportions of tetracoordinated $\mathrm{Ga}$ with a similar geometry as in $\mathrm{Ga}_{13}$. These polymers are supposed to exist in a very narrow $\mathrm{pH}$ range, rapidly forming Ga-hexa-coordinated hydroxide solids. More studies are needed to establish their exact structure and stability. The schematic structures of the $\mathrm{Ga}$ hydroxide polymers proposed to form in this study as a function of hydrolysis progress are presented in Fig. 11.

The results of our study on the hydrolysis of $\mathrm{Ga}\left(\mathrm{NO}_{3}\right)_{3}$ dilute solutions can be compared with Ga speciation calculated using thermodynamic data on Ga hydroxide complexes deduced from potentiometric and solubility studies carried out at Ga concentrations below $0.01 \mathrm{~m}$. In Fig. 12 the distribution of $\mathrm{Ga}$ hydroxide complexes in a $10^{-3} \mathrm{~m}$ Ga solution is calculated as a function of $\mathrm{pH}$ at $25{ }^{\circ} \mathrm{C}$. These calculations were performed at ionic strength 0.1 , using the equilibrium formation constants for the $\mathrm{Ga}(\mathrm{OH})_{1-4}$ mononuclear species from Bénézeth et al. (1997), and those for Ga polymers from Baes and Mesmer (1976). The generic formula " $\mathrm{Ga}_{26}(\mathrm{OH})_{26}^{13+"}$ " was tentatively ascribed by the latter authors to a set of different polymeric species including the $\mathrm{Ga}_{13}$ and $\mathrm{Ga}_{40}$ polycations which were detected via potentiometric titrations. It can be seen in Fig. 12 that, in a $10^{-3} \mathrm{~m} \mathrm{Ga}$ solution, polymeric species begin to form in significant amounts ( $>10 \%$ of total $\mathrm{Ga}$ ) above $\mathrm{pH}$ 3.5-3.7. Our EXAFS measurements show that, at this $\mathrm{pH}$, Ga speciation is almost entirely dominated by the $\mathrm{Ga}_{13}$ species. Thus, the available equilibrium constants for the Ga polymers underestimate significantly their stabilities. Our EXAFS results can therefore help future potentiometric and solubility studies to better quantify the stability of aqueous Ga polymers in dilute solutions.

\subsection{Stoichiometry and Structure of Ga-Si Aqueous Complexes}

EXAFS and NMR measurements reported in this study demonstrate that aqueous silica forms stable complexes with gallium via the constitution of $\mathrm{Ga}-\mathrm{O}-\mathrm{Si}$ bonds. In these complexes Ga exhibits a tetrahedral atomic environment with oxygens not only at basic and neutral, but also at moderately acid $\mathrm{pH}$, where it is normally hexa-coordinated with oxygens in its hydroxide complexes. The striking similarity of second and third Ga shell atomic environments found by EXAFS spectroscopy in our study implies that similar Ga-silicate complexes form over a wide $\mathrm{pH}$ range $(3 \leq \mathrm{pH} \leq 10)$. The $3.11-3.20 \AA \mathrm{Ga}-\mathrm{Si}$ distance determined in the second coordination shell of $\mathrm{Ga}$ corresponds to $\mathrm{Ga}-\mathrm{O}-\mathrm{Si}$ bond angles of $125^{\circ}-135^{\circ}$ and closely resembles $\mathrm{Ga}$ atomic environment in zeolite structures where tetrahedral $\mathrm{Ga}$ substitutes for silicon (or aluminum) in the zeolite framework rings composed typically of four to six $(\mathrm{Si}, \mathrm{Al}) \mathrm{O}_{4}$ tetrahedra (Barrer, 1982; Fricke et al., 2000). It can be thus assumed that these $\mathrm{Ga}-\mathrm{Si}$ distances correspond to aqueous $\mathrm{Ga}-\mathrm{Si}$ complexes having a cyclic structure. Cyclic gallosilicate species, which form by exchange of $\mathrm{SiO}_{4}$ and $\mathrm{GaO}_{4}$ tetrahedrons in the already existing silica cyclic polymers, were also reported for concentrated $\mathrm{Ga}-\mathrm{Si}$ solutions using NMR spectroscopy (Mortlock et al., 1992).

The second $\mathrm{Ga}-\mathrm{Si}$ distance evidenced in this study $\left(R_{2}=\right.$ $3.39 \pm 0.04 \AA$ ) matches $\mathrm{Ga}-\mathrm{O}-\mathrm{Si}$ angles of $165 \pm 5^{\circ}$. These 


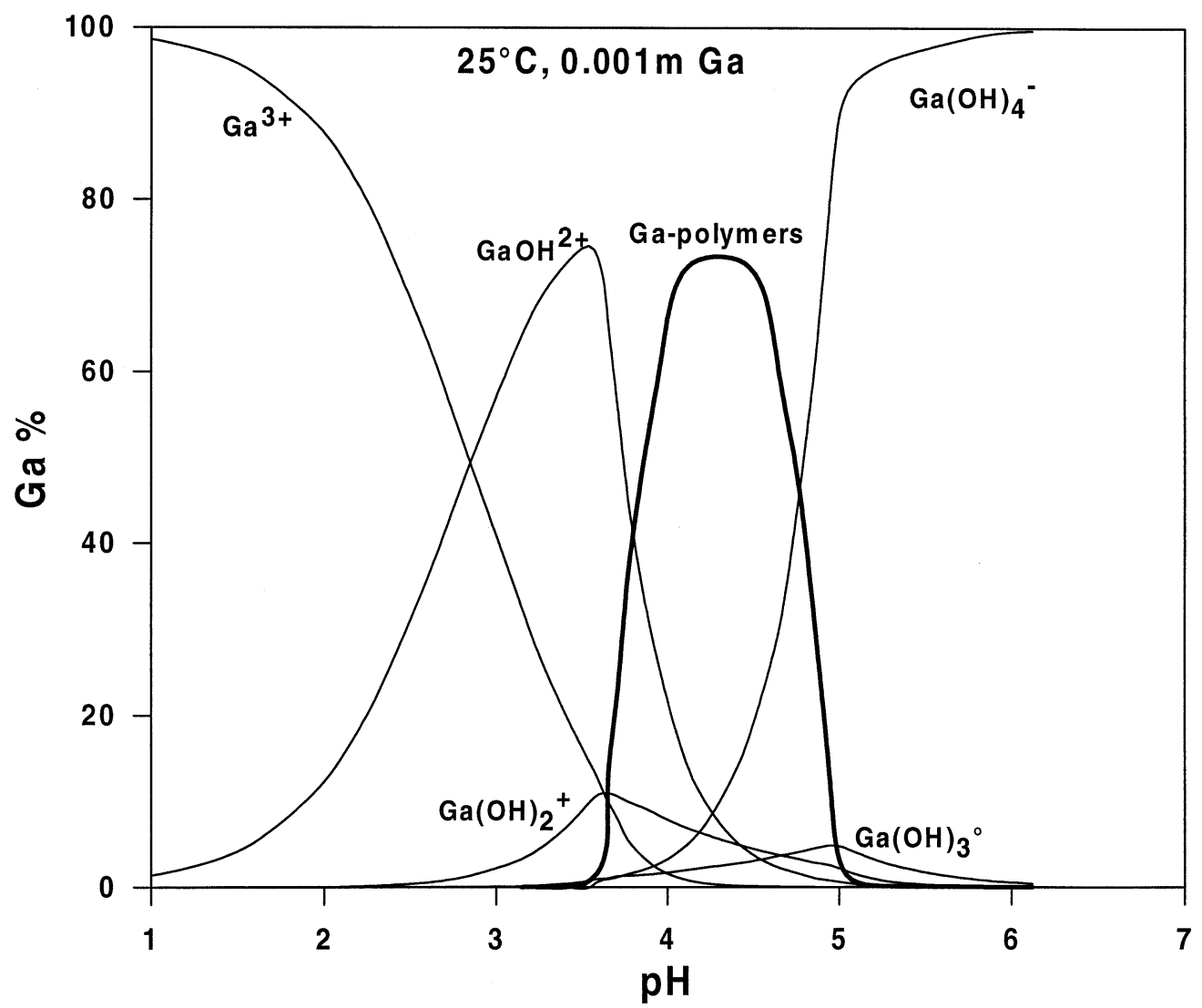

Fig. 12. Distribution of Ga hydroxide species in a $0.001 \mathrm{~m}$ Ga nitrate solution as a function of $\mathrm{pH}$ at $25^{\circ} \mathrm{C}$. Calculations were performed using the stability constants for Ga species reported by Baes and Mesmer (1976) and Bénézeth et al. (1997).

values are likely to correspond to noncyclic, chain-like complexes in which $\mathrm{GaO}_{4}$ is surrounded by two to four silicate anions. Note that similar di-, tri-, and tetrasilicate complexes were reported using NMR spectroscopy for $\mathrm{Al}\left(Q_{\mathrm{Al}}^{2}, Q_{\mathrm{Al}}^{3}\right.$, and $Q^{4}{ }_{\mathrm{Al}}$ ) in basic solutions with high $\mathrm{Si} / \mathrm{Al}$ ratios (Kinrade and Swaddle, 1989; Pokrovski et al., 1998). The tentative schematic structures of the Ga-Si complexes found in this study are represented in Figure 13.

Another type of $\mathrm{Ga}-\mathrm{Si}$ interactions inferred from EXAFS spectra of strongly acid solutions is likely to involve linkages between hexa-coordinated gallium and silicic acid. The $\mathrm{Ga}-\mathrm{Si}$ distance of $3.17 \AA$, found in a $0.005 \mathrm{~m} \mathrm{Ga}, 0.056 \mathrm{~m}$ Si solution at pH 2.7 (see Sect. 4.3.2), might correspond to silica forming double-corner linkages with two adjacent Ga octahedra. Similar geometries have been found in the case of $\mathrm{Fe}-\mathrm{Si}$ complexation (Pokrovski et al., 2001) or arsenate and selenate adsorption on Fe-hydroxides (Waychunas et al., 1993; Manceau and Charlet, 1994; Manceau, 1995). More measurements are required however to better quantify this type of $\mathrm{Ga}-\mathrm{Si}$ interaction in strongly acid solutions.

\subsection{Stabilities of Ga-Si Complexes in Natural Waters}

The results obtained in this study demonstrate, for the first time, an important effect of silica, at the atomic scale, on the hydrolysis of gallium. Through its complexation with gallium, aqueous silica greatly hampers the formation of $\mathrm{Ga}$ polymeric hydroxide species and thus the precipitation of Ga oxy-hydroxides at $\mathrm{pH}$ typical of natural waters $(\mathrm{pH}>3)$. An analogous effect of aqueous silica is observed for $\mathrm{Al}$ hydrolysis. For example, polymeric hydroxyalumino-silicate complexes were found to form in significant amounts at ambient temperature in the neutral $\mathrm{pH}$ range and serve as precursors for immogolite and allophane formation (Exley and Bishall, 1992, 1993; Xu and Harch, 1993). Moreover, ample evidence exists for Al-Si complex formation in basic solutions in a wide range of $\mathrm{Al}$ and Si concentrations (e.g., Guth et al., 1974a, 1974b; 1980; Wada and Wada, 1981; Kinrade and Swaddle, 1989; Gout et al., 2000, references therein). At the low $\mathrm{Ga}(\mathrm{Al})$ and $\mathrm{Si}$ concentrations of natural waters $\left(m_{\mathrm{Ga}}<10^{-6} \mathrm{~m}, m_{\mathrm{Al}}<10^{-4}, m_{\mathrm{Si}}<10^{-3} \mathrm{~m}\right.$, Bénézeth et al., 1997; Diakonov et al., 1997), both Ga (Al) and Si speciation is entirely dominated by monomeric hydroxide species. The silica linkages with tetrahedral and octahedral Ga, demonstrated in this study, imply two different mechanisms of $\mathrm{Si}$ interactions with ${ }^{[6]} \mathrm{Ga}$ and ${ }^{[4]} \mathrm{Ga}$ monomeric hydroxide species, respectively,

$$
\begin{aligned}
& { }^{[6]} \mathrm{Ga}(\mathrm{OH})_{n}\left(\mathrm{H}_{2} \mathrm{O}\right)_{6-n}^{3-n}+\mathrm{Si}(\mathrm{OH})_{4}^{\mathrm{o}} \\
& \quad=\left(\mathrm{H}_{2} \mathrm{O}\right)_{5-n}^{[6]} \mathrm{GaOSi}(\mathrm{OH})_{3}^{2-n}+\mathrm{H}_{3} \mathrm{O}^{+}, \quad 0 \leq n \leq 3, \mathrm{pH} \leq 4,
\end{aligned}
$$

$$
\begin{aligned}
{ }^{[4]} \mathrm{Ga}(\mathrm{OH})_{4}^{-} & +\mathrm{Si}(\mathrm{OH})_{4}^{\mathrm{o}} \\
& =(\mathrm{OH})_{3}^{[4]} \mathrm{GaOSi}(\mathrm{OH})_{3}^{-}+\mathrm{H}_{2} \mathrm{O} \quad \text { at } \mathrm{pH}>4 .
\end{aligned}
$$




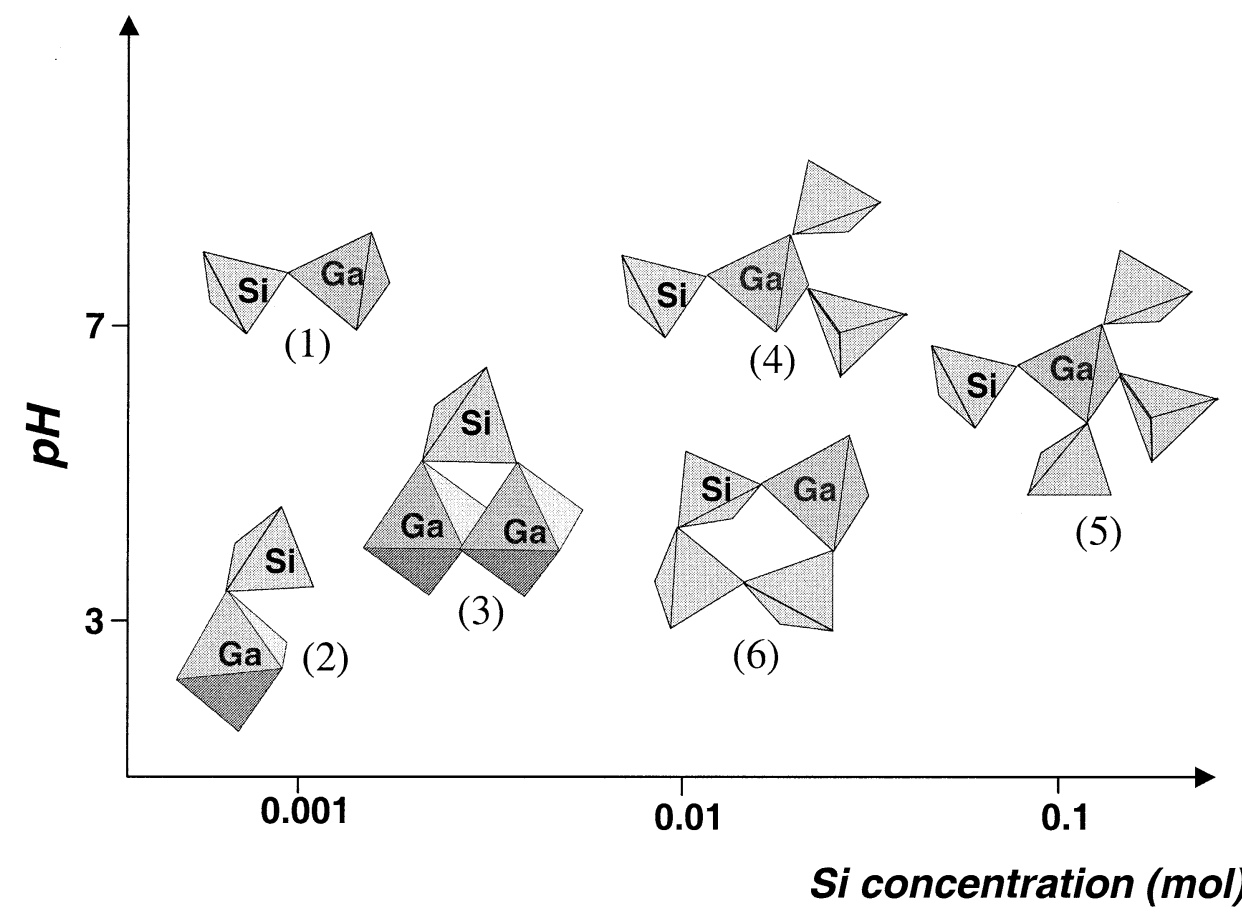

Fig. 13. Schematic structures of Ga-Si complexes proposed in this study from EXAFS and NMR measurements. Complexes $(4,5,6)$ were found to form in our experimental solutions at $\mathrm{pH}>2.7$ and $m_{\mathrm{Si}}>0.01 \mathrm{~m}$. Complexes $(2$ and $3)$ are likely to form in strongly acid solutions $(\mathrm{pH}<3)$ at moderate $\mathrm{Si}$ concentrations $\left(m_{\mathrm{Si}}<0.05 \mathrm{~m}\right)$. Complex $(1)$ is assumed to exist in neutral to basic dilute Si solutions based on the analogy with Al-Si species (Pokrovski et al., 1998).

The proposed reactions are analogous to those recently found for Al-Si interactions in very dilute solutions $\left(m_{\mathrm{Al}, \mathrm{Si}} \leq 0.001\right.$ $\mathrm{m})$, where $\mathrm{Al}^{3+}$ and $\mathrm{Al}(\mathrm{OH})_{4}^{-}$form 1:1 complexes with silicic acid, respectively, at acid and basic pH (Pokrovski et al., 1996 and references therein; Pokrovski et al., 1998).

The first reaction is likely to proceed through the substitution of a water molecule by a silicic acid ligand in the first hydration sphere of the hexa-coordinated $\mathrm{Ga}^{3+}$ cation (Pokrovski, 1996). This mechanism is similar to that assumed for the hydrolysis of metallic di- and tri-valent cations (Jolivet et al., 1994). The similarity between the mechanisms of formation of hydroxide and silicate complexes in acid solution is illustrated in Fig. 14, where the equilibrium constants of metal-silica complexation reaction (analogous to reaction (1) for $n=0$ ) available in the literature for different cations $\left(\mathrm{Na}^{+}, \mathrm{Ca}^{2+}, \mathrm{Mg}^{2+}, \mathrm{UO}_{2}^{2+}\right.$, $\mathrm{La}^{3+}, \mathrm{Al}^{3+}, \mathrm{Fe}^{3+}$ ) are plotted versus their first hydrolysis constants. The good linear correlation (squared correlation coefficient $=0.97$ ) apparent in this figure suggests that both $\mathrm{OH}^{-}$ and $\mathrm{OSi}(\mathrm{OH})_{3}^{-}$, which contain negatively charged oxygen donors, form with many metal ions complexes of similar structures and thermodynamics. Similar free energy relationships were demonstrated for many metallic cations between their hydroxide and $\mathrm{O}$-containing organic ligand complexes in aqueous solution (Martell and Hancock, 1996), or complexes adsorbed on oxy-hydroxide mineral surfaces (Stumm, 1992). The linear relationship presented in our study allows estimation of the stability of metal-silicate complexes for which there are no available data. The equilibrium constant at $25{ }^{\circ} \mathrm{C}$ for reaction (1) between $\mathrm{Ga}^{3+}$ and silicic acid can be thus estimated from the above correlation and using the first hydrolysis constant of
$\mathrm{Ga}^{3+}$ from Bénézeth et al. (1997): $\log K_{1}^{\mathrm{Si}}=-0.7 \pm 0.2$. Speciation calculations carried out using this constant indicate that the $\mathrm{GaOSi}(\mathrm{OH})_{3}^{2+}$ complex can account for only $10 \%$ to $15 \%$ of the total $\mathrm{Ga}$ at $\mathrm{pH}$ between 3 and 4 in the presence of $30 \mathrm{ppm}$ of aqueous silica.

Complexes between the monomeric hydroxide species $\left(\mathrm{GaOH}^{2+}, \mathrm{Ga}(\mathrm{OH})_{2}^{+}\right.$, and $\left.\mathrm{Ga}(\mathrm{OH})_{3}^{\mathrm{o}}\right)$ and silicic acid are expected to be even weaker than that with $\mathrm{Ga}^{3+}$ because the decrease of species charge should diminish metal-silica electrostatic attractions. This has been verified for $\mathrm{Al}(\mathrm{OH})_{n}$-acetate complexes (Bénézeth et al., 1994) and for $\mathrm{Al}(\mathrm{OH})_{1-3}$-silicate complexes in which $\mathrm{Al}$ exists in sixfold coordination (Pokrovski et al., 1996; Salvi et al., 1998). Thus, by analogy with $\mathrm{Al}$, silica complexes with the intermediate hydrolyzed Ga species in coordination 6 can be assumed to be negligible at silica concentrations of natural waters.

The formation of stable silicate species with gallium in fourfold coordination as demonstrated in this study, implies that, like for $\mathrm{Al}, \mathrm{Ga}-\mathrm{Si}$ complexation is much stronger when the metal takes the tetrahedral coordination. This is consistent with the formation of $\mathrm{Ga}-\mathrm{O}-\mathrm{Si}$ covalent bonds, similar to those observed for A1-Si complexes. The percentage of complexed $\mathrm{Ga}$ and the number of silicate ligands can be qualitatively related to the intensities of $\mathrm{Ga}-\mathrm{Si}$ contributions to the Fourier transforms of EXAFS spectra obtained in this study. In $\mathrm{Ga}-\mathrm{Si}$ bearing alkaline solutions, these intensities increase with decreasing $\mathrm{pH}$ from 11 to 8 at the same silica concentration (Fig. 10a). This evolution of the stability of $\mathrm{Ga}-\mathrm{Si}$ complexes with $\mathrm{pH}$ is very similar to that observed for $\mathrm{Al}-\mathrm{Si}$ complexes from potentiometric and NMR (Pokrovski et al., 1998), and Raman 


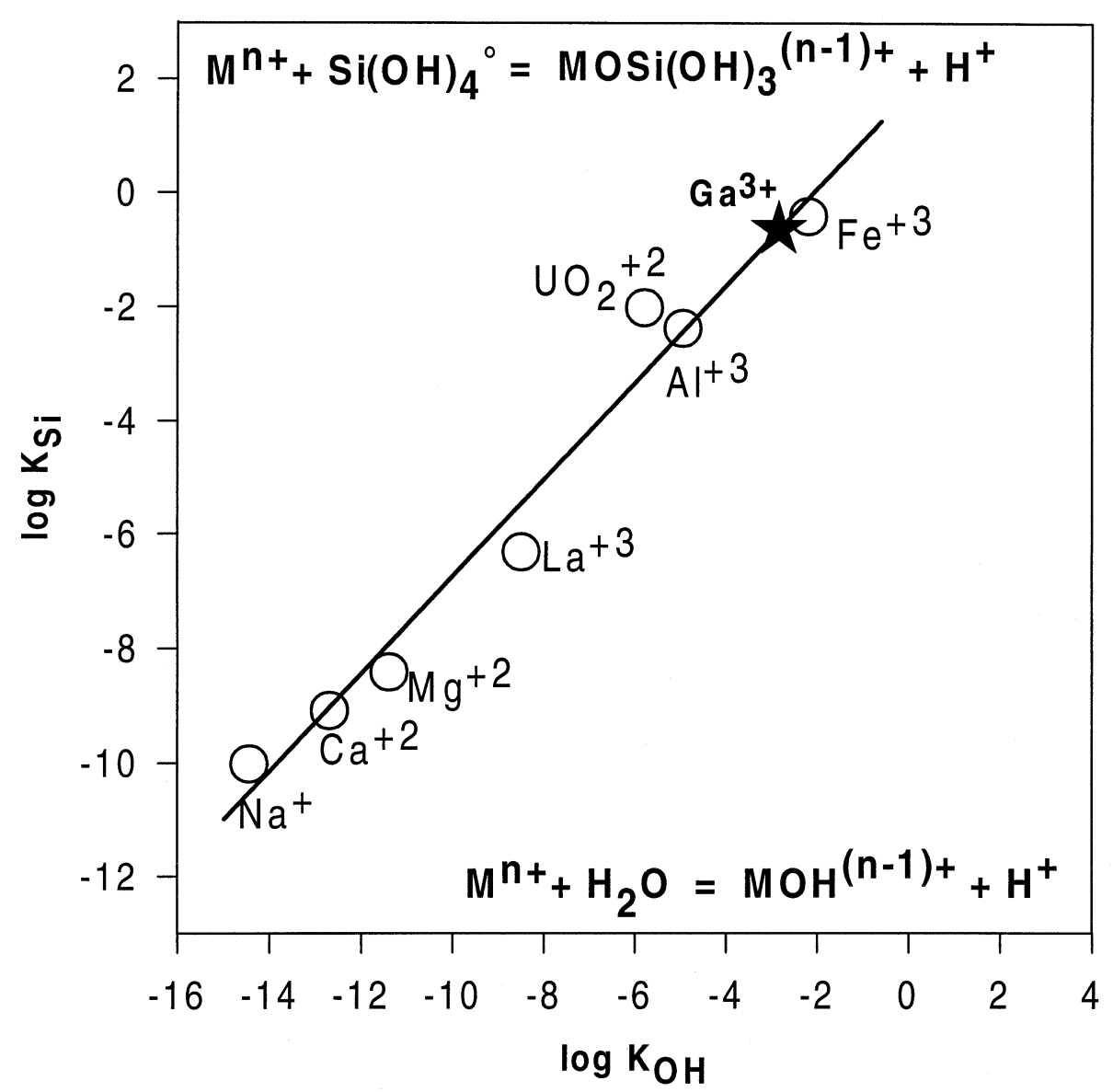

Fig. 14. Logarithm of the complex formation constant between a metal cation and aqueous silicic acid $\left(K_{\mathrm{Si}}\right)$ as a function of the logarithm of the first hydrolysis constant of the metal $\left(K_{\mathrm{OH}}\right)$ at $25{ }^{\circ} \mathrm{C}$. Stability constants of metal-silica complexes were taken from Sillen and Martell (1964) for Na, Santschi and Schindler (1974) for Ca and Mg, Pokrovski for La, Pokrovski et al. (1996) for Al, Satoh and Chopin (1992) for $\mathrm{UO}_{2}{ }^{2+}$, and Weber and Stumm (1965) and Olson and Melia (1973) for Fe. The hydrolysis constants for the metals were taken from Baes and Mesmer (1976). The circles stand for the data for corresponding cation, but the solid line represents a linear regression of these data: $\log K_{\mathrm{Si}}=0.85 \log K_{\mathrm{OH}}+1.8$ $\left(R^{2}{ }_{\mathrm{xy}}=0.97\right)$. The star denotes $\mathrm{Ga}^{3+}$ cation for which $\log K_{\mathrm{Si}}$ was determined from the above correlation using the $\mathrm{Ga}^{3+}$ first hydrolysis constant from Bénézeth et al. (1997).

spectroscopy measurements (Gout et al., 2000). By analogy with aluminum, it can be suggested that, at the low silica and gallium concentrations of natural waters, the dimeric complex between $\mathrm{Ga}(\mathrm{OH})_{4}^{-}$and silicic acid formed according to reaction (2) should be most probable. In the absence of data for metals other than $\mathrm{Al}$, it is however difficult to quantify the stability of this ${ }^{[4]} \mathrm{Ga}-\mathrm{Si}$ species. If we assume, in the first appoximation, that the equilibrium constant of reaction (2) for $\mathrm{Ga}(\mathrm{OH})_{4}^{-}$is equal to that of the analogous reaction with $\mathrm{Al}(\mathrm{OH})_{4}^{-}\left(\log K_{2}{ }^{\mathrm{Al}}\right.$ $=3.7 \pm 0.2$ at $25{ }^{\circ} \mathrm{C}$, Pokrovski et al., 1998), the $(\mathrm{OH})_{3} \mathrm{GaOSi}(\mathrm{OH})_{3}^{-}$complex would account for about $90 \%$ of total $\mathrm{Ga}$ in the $\mathrm{pH}$ range from 4.5 to 10 , for silica-rich soil solutions and waters from tropical watersheds $(\sim 20-30 \mathrm{ppm}$ Si, Viers et al., 1997). Taking account of the easier tendency of $\mathrm{Ga}$ than $\mathrm{Al}$ to pass in tetrahedral coordination with increasing $\mathrm{pH}$ (above $\mathrm{pH} 4$ and 7 for $\mathrm{Ga}$ and $\mathrm{Al}$, respectively), Ga-Si complexes might be even more important than their $\mathrm{Al}$ analogs. More work is however needed to quantify their stabilities in dilute natural fluids. The results of our study imply that explicit account for $\mathrm{Ga}-\mathrm{Si}$ complexing should be done when analyzing
Ga mobility in surficial waters and the incorporation of this trace metal in clays and iron and aluminum oxy-hydroxides.

\section{CONCLUDING REMARKS}

The results obtained in this study showed that $\mathrm{Ga}$ (III) hydrolysis in dilute solutions proceeds at early stages via formation of ${ }^{[6]} \mathrm{Ga}$ polynuclear hydroxide complexes in which $\mathrm{GaO}_{6}$ octahedra share common corners and edges, which is similar to $\mathrm{Fe}(\mathrm{III}), \mathrm{Al}$, and $\mathrm{Cr}$ (III) hydrolysis. As hydrolysis progresses, these species are rapidly replaced by the $\mathrm{Ga}_{13}$ polycation, structurally similar to $\mathrm{Al}_{13}$, which becomes the dominant species at $\mathrm{OH} / \mathrm{Ga}$ ratios $(R)$ of $\sim 2$. At higher $R$, and just before the Ga-hydroxide precipitation, both EXAFS and NMR measurements provide evidence that larger, less ordered, polynuclear Ga species with significant proportions of ${ }^{[4]} \mathrm{Ga}$ form at the expense of $\mathrm{Ga}_{13}$. This new feature has not been observed for other $\mathrm{M}^{3+}$ cations like $\mathrm{Al}, \mathrm{Cr}$ or $\mathrm{Fe}$. At later hydrolysis stages $(R>3.5), \mathrm{Ga}$, like $\mathrm{Al}$, exhibits a tetrahedral coordination 
corresponding to the dominant $\mathrm{Ga}(\mathrm{OH})_{4}^{-}$species, in agreement with previous studies.

Important changes in Ga hydrolysis have been detected in the presence of aqueous silica. Gallium is tetra-coordinated both in basic and acid solutions $(\mathrm{pH} \geq 3)$, and forms stable gallium-silicate complexes in which it binds via oxygen bridges to $\sim 2 \pm 1$ silicons at $3.16 \pm 0.05 \AA$, and $\sim 2 \pm 1$ silicons at $3.39 \pm 0.03 \AA$. This $\mathrm{Ga}$ atomic environment is likely to correspond to cyclic $\mathrm{Ga}-\mathrm{Si}_{2-3}$ and chain-like $\mathrm{GaSi}_{2-4}$ species, formed via covalent $\mathrm{Ga}-\mathrm{O}-\mathrm{Si}$ bonds. At very acid $\mathrm{pH}$ $(<2.8)$ and moderate silica concentrations, the presence of another type of $\mathrm{Ga}-\mathrm{Si}$ complex, in which $\mathrm{Ga}$ remains hexacoordinated and binds to silicon tetrahedra via the $\mathrm{GaO}_{6}$ octahedron corners, has been also detected. The evolution of both ${ }^{[4]} \mathrm{Ga}-$ and ${ }^{[6]} \mathrm{Ga}$-silicate complexes with $\mathrm{pH}$ and Si concentration is similar to that for the analogous Al-Si species (Pokrovski et al., 1998; Salvi et al., 1998). This analogy allows, for the first time, estimation of the stabilities of the simplest $\mathrm{Ga}-\mathrm{Si}$ complexes which are likely to form in dilute natural solutions. Equilibrium calculations using the derived stability constants for the ${ }^{[6]} \mathrm{GaOSi}(\mathrm{OH})_{3}^{2+}$ and ${ }^{[4]} \mathrm{Ga}(\mathrm{OH})_{3} \mathrm{OSi}(\mathrm{OH})_{3}^{-}$complexes analogous to those formed by $\mathrm{Al}$ in very dilute solutions, indicate that, as for aluminum, silicic acid greatly hampers $\mathrm{Ga}$ hydrolysis and enhances Ga mobility in natural waters.

The similarity of $\mathrm{Ga}$ and $\mathrm{Al}$ hydrolysis and interactions with aqueous silica demonstrated in this study provides new insights for understanding aluminosilicate precipitation and trace element incorporation into solid phases in surficial aquatic environments. Polymeric Ga-Si and Al-Si complexes formed from supersaturated solutions could be viewed as precursors for the formation of $\mathrm{Al} / \mathrm{Ga}$-bearing minerals. Different proportions of ${ }^{[4]} \mathrm{Al}$ to ${ }^{[6]} \mathrm{Al}$ observed in secondary aluminosilicates are likely to reflect, at least partially, the amount and structures of Al-Si complexes existing in the solution from which these solids have precipitated.

The combination of XAFS and NMR spectroscopy was shown to have great potential in deciphering the processes of metal hydrolysis/condensation and complexation in aquatic media. Ab initio quantum mechanics calculations can be also effectively coupled with these in situ spectroscopic methods to help constrain the structures and stabilities of aqueous species. Work is currently in progress to quantify $\mathrm{Al}-\mathrm{Si}$ and $\mathrm{Fe}(\mathrm{III})-\mathrm{Si}$ interactions in dilute aqueous solution using this combined approach.

Acknowledgments - We are grateful to the IF CRG commission of the ESRF (Grenoble) for providing beamtime and access to the synchrotron facility. We would like to thank Yvonne Soldo, Olivier Proux, and Jean-Jacques Menthonnex for their generous help and professional assistance during XAFS measurements at BM 32 beamline of the ESRF. Daniel Aberdam and Marcus Winterer are thanked for providing us with their programs for XAFS treatment (SEDEM and XAFS, respectively). We are grateful to Marc Vedrenne who performed NMR measurements. We are indebted to Jacques Roux for his great help with software installation and running, and Jean-Michel Bény for his advice on crystallography. Insightful comments by the Associate Editor, David Wesolowski, and three anonymous reviewers greatly impoved the presentation and clarity of this paper.

Associate editor: D. J. Wesolowski

\section{REFERENCES}

Aberdam D. (1998) SEDEM, a software package for EXAFS extraction and modelling. J. Synchrotron Rad. 5, 1287-1297.

Ahman J., Svensson G., and Albertsson J. (1996) A reinvestigation of $\beta$-gallium oxide. Acta Crystallogr. C 52, 1336-1338.

Akitt J. W., Greenwood N. N., Khandelwal B. L., and Lester G. D. (1972) ${ }^{27} \mathrm{Al}$ nuclear magnetic resonance studies of the hydrolysis and polymerisation of the hexa-aquo-aluminum(III) cation. J. Chem. Soc. Dalton Trans. 1972, 604-610.

Akitt J. W. and Elders J. M. (1988) Multinuclear magnetic resonance studies of the hydrolysis of aluminum (III). Part 8 . Base hydrolysis monitored at very high magnetic field. J. Chem. Soc. Dalton Trans. $1347-1355$.

Ankudinov A. L. and Rehr J. J. (1997) Relativistic spin-dependent X-ray absorption theory. Phys. Rev. B 56, R1712-R1715.

Baes C. F. Jr. and Mesmer R. E. (1976). The Hydrolysis of Cations. Wiley.

Barrer R. M. (1982) Hydrothermal Chemistry of Zeolites. Academic.

Bénézeth P., Castet S., Dandurand J.-L., Gout R., and Schott J. (1994) Experimental study of aluminum-acetate complexing between 60 and $200{ }^{\circ}$ C. Geochim. Cosmochim. Acta 58, 4561-4571.

Bénézeth P., Diakonov I., Pokrovski G. S., Dandurand J.-L., Schott J., and Khodakovsky I. L. (1997) Gallium speciation in aqueous solution. Experimental study and modelling. Part II. Solubility of $\alpha$-GaOOH in acidic solutions from 150 to $250{ }^{\circ} \mathrm{C}$ and hydrolysis constants of gallium (III) to $300{ }^{\circ} \mathrm{C}$. Geochim. Cosmochim. Acta 61, 1345-1357.

Behrens P., Kosslick H., Tuan V. A., Fröba M., and Niessendorfer F. (1995) X-ray absorption spectroscopic study on the structure and crystallization of Ga-containing MFI-type zeolites. Microporous Mater. 3, 433-441.

Birchall J. D., Exley C., Chappell J. S., and Phillips M. J. (1989) Acute toxicity of aluminium to fish eliminated in silicon-rich acid waters. Nature 338, 146-148.

Bonnin D., Calas G., Suquet H., and Pezerat H. (1985) Site occupancy of $\mathrm{Fe}^{3+}$ in Galfield nontronite: a spectroscopic study. Phys. Chem. Miner. 12, 55-64.

Bottero J. Y., Manceau A., Villieras F., and Tchoubar D. (1994) Structure and mechanisms of formation of $\mathrm{FeOOH}(\mathrm{Cl})$ polymers. Langmuir 10, 316-319.

Bradley S. M., Kydd R. A., Yamdagni R. (1990b) Detection of a new polymeric species formed through the hydrolysis of gallium (III) salt solutions. J. Chem. Soc. Dalton Trans., 413-417.

Bradley S. M., Kydd R. A., and Yamdagni R. (1990a) Study of the hydrolysis of combined $\mathrm{Al}^{3+}$ and $\mathrm{Ga}^{3+}$ aqueous solutions: Formation of an extremely stable $\mathrm{GaO}_{4} \mathrm{Al}_{12}(\mathrm{OH})_{24}\left(\mathrm{H}_{2} \mathrm{O}\right)_{12}{ }^{7+}$ polyoxycation. Magn. Res. Chem. 28, 746-750.

Browne B. A. and Driscoll C. T. (1992) Soluble aluminum silicates: stoichiometry, stability, and implications for environmental geochemistry. Science 256, 1667-1670.

Combes J. M., Manceau A., Calas G., and Bottero J. Y. (1989) Formation of ferric oxides from aqueous solutions: A polyhedral approach by X-ray absorption spectroscopy: I. Hydrolysis and formation of ferric gels. Geochim. Cosmochim. Acta 53, 583-594.

Crosier E. D., Rehr J. J., and Ingalls R. (1988) Amorphous and liquid systems. In X-ray Absorption. Principles, Applications, Techniques of EXAFS, SEXAFS and XANES (ed. D. C. Koningsberger and R. Prins). pp. 373-442. Wiley-Interscience.

Decarreau A., Bonnin D., Badaut-Trauth D., Couty R., and Kaiser P. (1987) Synthesis and crystallogenesis of ferric smectite by evolution of $\mathrm{Si}-\mathrm{Fe}$ coprecipitates in oxidizing conditions. Clay Minerals 22, 207-223.

Diakonov I., Pokrovski G. S., Benezeth P., Schott J., Dandurand J.-L., and Escalier J. (1997) Gallium speciation in aqueous solution. Experimental study and modelling. Part I. Thermodynamic properties of $\mathrm{Ga}(\mathrm{OH})_{4}^{-}$to $300{ }^{\circ} \mathrm{C}$. Geochim. Cosmochim. Acta 61, 1333-1343.

Doelsch E., Rose J., Masion A., Bottero J.Y., Nahon D., and Bertch P. M. (2000) Speciation and crystal chemistry of iron (III) chloride hydrolyzed in the presence of $\mathrm{SiO}_{4}$ ligands. 1. An Fe K-edge EXAFS study. Langmuir 16, 4726-4731.

Dooryhee E., Greaves G. N., Steel A. T., Townsend R. P., Carr S. W., Thomas J. M., and Catlow C. R. A. (1990) Structural studies of 
high-area zeolitic adsorbents and catalysts by a combination of high-resolution X-ray powder diffraction and X-ray absorption spectroscopy. Faraday Discuss. Chem. Soc. 89, 119-136.

Exley C. and Birchall J. D. (1992) Hydroxyaluminosilicate formation in solutions of low aluminium concentration. Polyhedron 11, 19011907.

Exley C. and Birchall J. D. (1993) A mechanism of hydroxyaluminosilicate formation. Polyhedron 12, 1007-1017.

Farges F. (1996) Does Zr-F complexation occur in magmas? Chem. Geol. 127, 253-268.

Farges F., Brown G. E. Jr., and Rehr J. J. (1996a) Coordination chemistry of Ti(IV) in silicate glasses and melts: I. XAFS study of titanium coordination in oxide model compounds. Geochim. Cosmochim. Acta 60, 3023-3038.

Farges F., Brown G. E. Jr., Navrotsky A., Gan H., and Rehr J. J. (1996b) Coordination chemistry of Ti(IV) in silicate glasses and melts: III. Glasses and melts from ambient to high temperatures. Geochim. Cosmochim. Acta 60, 3055-3065.

Farmer V. C., Fraser A. R., and Tait J. M. (1977) Synthesis of imologite: a tubular aluminosilicate polymer. J. Chem. Soc. Chem. Comm. 1977, 462-463.

Farmer V. C., Fraser A. R., and Tait J. M. (1979) Characterization of the chemical structures of natural and synthetic aluminosilicate gels and sols by infrared spectroscopy. Geochim. Cosmochim. Acta 43, $1417-1420$.

Farmer V. C. and Lumsdon D. G. (1994) An assessment of complex formation between aluminium and silicic acid in acidic solutions. Geochim. Cosmochim. Acta 58, 3331-3334.

Faust B. C., Labiosa W. B., Dai K. H., MacFall J. S., Browne B. A., Ribeiro A. A., and Richter D. D. (1995) Speciation of aqueous mononuclear $\mathrm{Al}(\mathrm{III})$-hydroxo and other $\mathrm{Al}(\mathrm{III})$ complexes at concentrations of geochemical relevance by ${ }^{27} \mathrm{Al}$ nuclear magnetic resonance spectroscopy. Geochim. Cosmochim. Acta 59, 2651-5661.

Fendorf S. E., Lamble G. M., Stapleton M. G., Kelley M. J., and Sparks D. L. (1994) Mechanisms of chromium (III) sorption on silica. 1. $\mathrm{Cr}$ (III) surface structure derived by extended X-ray absorption fine structure spectroscopy. Environ. Sci. Technol. 28, 284-289.

Fricke R., Kosslick H., Lischke G., and Richter M. (2000) Incorporation of gallium into zeolites: Syntheses, properties and catalytic application. Chem. Rev. 100, 2303-2405.

Gout R., Pokrovski G. S., Schott J., and Zwick A. (1999) A Raman spectroscopy study of aluminum-silica complexing in aqueous solution. J. Sol. Chem. 28, 73-82.

Gout R., Pokrovski G. S., Schott J., and Zwick A. (2000) Raman spectroscopic study of aluminum silicate complexing at $20{ }^{\circ} \mathrm{C}$ in basic solutions. J. Sol. Chem. 29, 1173-1186.

Guth J-L., Caullet P., and Wey R. (1974a) Contribution à l'étude du mécanisme de formation des zéolites. I. Mise en évidence de complexes aluminosilicates solubles par acidimétrie. Bull. Soc. Chim. Fr. 1974, $1758-1762$.

Guth J-L., Caullet P., and Wey R. (1980) Contribution à l'étude du mécanisme de formation des zéolites. II. Mise en évidence de complexes aluminosilicates solubles par conductométrie. Bull. Soc. Chim. Fr., 2363-2366.

Guth J-L., Caullet P., Jacques P., and Wey R. (1980) Contribution à l'étude du mécanisme de formation des zéolites. IV. - Mise en évidence de complexes aluminosilicates dans des solutions aqueuses basiques contenant des cations sodium par spectroscopie RamanLaser. Bull. Soc. Chim. Fr., 121-126.

Higby P. L., Shelby J. E., Phillips J. C., and Legrand A. D. (1988) EXAFS study of alkali gallosilicate glasses. J. Non-Cryst. Solids 105, 139-148.

Johanson G. (1962a) On the crystal structure of the basic aluminum sulfate $13 \mathrm{Al}_{2} \mathrm{O}_{3} \cdot 6 \mathrm{SO}_{3} \cdot \mathrm{xH}_{2} \mathrm{O}$. Ark. Kemi 20, 321-342.

Johanson G. (1962b) The crystal structures of $\left[\mathrm{Al}_{2}(\mathrm{OH})_{2}\left(\mathrm{H}_{2} \mathrm{O}\right)_{8}\right]\left(\mathrm{SO}_{4}\right)_{2}$ - $2 \mathrm{H}_{2} \mathrm{O}$ and $\left[\mathrm{Al}_{2}(\mathrm{OH})_{2}\left(\mathrm{H}_{2} \mathrm{O}\right)_{8}\right]\left(\mathrm{SeO}_{4}\right)_{2} \cdot 2 \mathrm{H}_{2} \mathrm{O}$. Acta Chem. Scand. 16, 403-420.

Jolivet J-P., Henry M., and Livage J. (1994) De la Solution à l'Oxyde. InterEditions and CNRS Editions.

Kinrade S. D. and Swaddle T. W. (1989) Direct detection of aluminosilicate species in aqueous solution by silicon-29 and aluminum-27 NMR spectroscopy. Inorg. Chem. 28, 1952-1954.
Konhauser K. O. and Ferris F. G. (1996) Diversity of iron and silica precipitation by microbial mats in hydrothermal water, Iceland: Implications for Precambrian iron formations. Geology 24, 323-326.

Koroleff F. (1976) Determination of silicon. In Methods of Seawater Analysis (ed. K. Grassnoff). Springer-Verlag.

Lindqvist-Reis P., Munoz-Paez A., Diaz-Moreno S., Pattanail S., Parsson I., and Sandstom M. (1998) The structure of the hydrated $\mathrm{Ga}(\mathrm{III}), \mathrm{In}(\mathrm{III})$ and $\mathrm{Cr}(\mathrm{III})$ ions in aqueous solutions. A large angle X-ray scattering and EXAFS study. Inorg. Chem. 37, 6675-6683.

Manceau A. and Charlet L. (1994) The mechanism of selenate adsorption on goethite and hydrous ferric oxide. J. Colloid. Interface Sci. 168, 87-93.

Manceau A. (1995) The mechanism of anion adsorption on iron oxides: Evidence for the bonding of arsenate tetrahedra on free $\mathrm{Fe}(\mathrm{O}, \mathrm{OH})_{6}$ edges. Geochim. Cosmochim. Acta 59, 3647-3653.

Martell A. E. and Hancock R. D. (1996) Metal Complexes in Aqueous Solutions. Plenum.

Mayer T. D. and Jarrell W. M. (1996) Formation and stability of iron(II) oxydation products under natural concentrations of dissolved silica. Water Res. 30, 1208-1214.

Michot L. J., Montargès-Pelletier E., Lartiges B. S., d'Espinose de la Caillerie J-B., and Briois V. (2000) Formation mechanism of the $\mathrm{Ga}_{13}$ Keggin ion: A combined EXAFS and NMR study. J. Am. Chem. Soc. 122, 6048-6056.

Mortlock R. F., Bell A. T., and Radke C. J. (1992) ${ }^{29} \mathrm{Si}$ and ${ }^{71} \mathrm{Ga}$ NMR investigations of alkylammonium gallosilicate solutions. J. Phys. Chem. 96, 2968-2975.

Nenoff T. M., Harrison W. T. A., Gier T. E., Keder N. L., Zaremba C. M., Srdanov V. I., Nicol J. T., and Stucky G. D. (1994) Structural and chemical investigations of $\mathrm{Na}_{3}\left(\mathrm{ABO}_{4}\right)_{3} \cdot 4 \mathrm{H}_{2} \mathrm{O}$-type sodalite phases. Inorg. Chem. 33, 2472-2480.

Okabe K., Matsubayashi N., Sayama K., Arakawa H., and Nishijima A. (1991) EXAFS investigation of pentasil-structured gallium-containing metallosilicates. Bull. Chem. Soc. Jpn. 64, 2602-2604.

Öhman L-O. and Edlund U. (1996) Aluminum-27 NMR of solutions. In Encyclopedia of NMR (eds. D. M. Grant and R.K. Harris), pp. 742-751. Wiley.

Olson L. L. and O'Melia C. R. (1973) The interactions of Fe(III) with $\mathrm{Si}(\mathrm{OH})_{4}$. J. Inorg. Nucl. Chem. 35, 1977-1985.

Pokrovski G. S. (1996) Etude expérimentale du comportement du germanium, du silicium et de l'arsenic et de la complexation de l'aluminium avec la silice dans les solutions naturelles. Thèse de Doctorat de l'Université Paul-Sabatier.

Pokrovski G. S. and Schott J. (1998) Experimental study of the complexation of silicon and germanium with aqueous organic species. Implications for $\mathrm{Ge}$ and $\mathrm{Si}$ transport and the $\mathrm{Ge} / \mathrm{Si}$ ratio in natural waters. Geochim. Cosmochim. Acta 62, 3413-3428.

Pokrovski G. S., Martin F., Hazemann J.-L., and Schott J. (2000) An $\mathrm{X}$-ray absorption fine structure spectroscopy study of germaniumorganic ligand complexes in aqueous solution. Chem. Geol. 163, $151-165$.

Pokrovski G. S., Schott J., Harrichoury J.-C., and Sergeyev A. S. (1996) The stability of aluminum silicate complexes in acidic solutions from 25 to $150{ }^{\circ} \mathrm{C}$. Geochim. Cosmochim. Acta 60, 2495-2501.

Pokrovski G. S., Schott J., Hazemann J.-L., Martin F., Farges F., and Pokrovsky O.S. (2001) An X-ray absorption fine structure spectroscopy study of iron(III)-silica and gallium-silica complexes in aqueous solution: Implications for the hydrolysis and the formation of iron and aluminum oxy-hydroxides and silicates. European Union of Geosciences-XI. April 2001. Journal of Conference Abstracts on CD-Rom, Vol. 6, No. 1.

Pokrovski G. S., Schott J., Salvi S., Gout R., and Kubicki J. D. (1998) Structure and stability of alumino-silicate complexes in neutral to basic solutions. Experimental study and molecular orbital calculations. Min. Mag. 62A, 1194-1196.

Press W. H., Flannery B. P., Teukolsky S. A., and Vetterling W. T. (1986) Numerical Recipes-The Art of Scientific Computing. Cambridge University Press.

Pye M. F., Birtill J. J., and Dickens P. G. (1977) $\alpha$-Gallium oxide deuteriohydroxide: A power neutron diffraction investigation. Acta Crystalloar B. 33, 3224-3226. 
Salvi S., Pokrovski G. S., and Schott J. (1998) Experimental investigation of aluminum-silica aqueous complexing at $300{ }^{\circ} \mathrm{C}$. Chem. Geol. 151, 51-67.

Santschi P. H. and Schindler P. W. (1974) Complex formation in the ternary systems $\mathrm{Ca}-\mathrm{H}_{4} \mathrm{SiO}_{4}-\mathrm{H}_{2} \mathrm{O}$ and $\mathrm{Mg}-\mathrm{H}_{4} \mathrm{SiO}_{4}-\mathrm{H}_{2} \mathrm{O}$. J. Chem. Soc. Dalton Trans., 181-184.

Satoh I. and Choppin G. R. (1992) Interaction of uranyl (VI) with silicic acid. Radiochim. Acta 56, 85-87.

Sillen L. G. and Martell A. E. (1976) Stability Constants of Metal-Ion Complexes: Special Publication No. 17. The Chemical Society.

Schwertmann U. and Thalmann H. (1976) The influence of Fe(II), Si, and $\mathrm{pH}$ on the formation of lepidocrocite and ferrihydrite during oxidation of aqueous $\mathrm{FeCl}_{2}$ solutions. Clay Miner. 11, 189-200.

Soldo Y., Hazemann J. L., Aberdam D., Inui M., Tamura K., Raoux D., Pernot E., Jal J. F., and Dupuy-Philon J. (1998) Semiconductor-tometal transition in fluid selenium at high pressure and temperature: An investigation using X-ray absorption spectroscopy. Phys. Rev. B. 57, 258-268.

Stern E. A. (1993) Number of relevant independent points in x-rayabsorption fine-structure spectra. Phys. Rev. B. 48, 9825-9827.

Stumm W. (1992) Chemistry of the Solid-Water Interface. Wiley.

Teo B. K. (1986) EXAFS: Basic Principles and Data Analysis. Inorganic Chemistry Concepts 9 . Springer-Verlag.

Thomas F., Masion A., Bottero J. Y., Rouiller J., Montigny F., and Genévier F. (1993) Aluminum (III) speciation with hydroxy carboxylic acids. ${ }^{27} \mathrm{Al}$ NMR study. Environ. Sci. Technol. 27, 2511-2516.

Vempati R. K. and Loeppert R. H. (1989) Influence of structural and adsorbed $\mathrm{Si}$ on the transformation of synthetic ferrihydrite. Clays Clay Miner. 37, 273-279.
Viers J., Dupré B., Polve M., Schott J., Dandurand J.-L., and Braun J.-J. (1997) Chemical weathering in the drainage basin of a tropical watershed (Nsimi-Zoétélé site, Cameroon): comparison between organic-poor and organic-rich waters. Chem. Geol. 140, 181-206.

Wada S-I. and Wada K. (1981) Reactions between aluminate ions and orthosilicic acid in dilute, alkaline to neutral solutions. Soil Sci. 132, 267-273.

Waychunas G. A., Rea B. A., Fuller C. C., and Davis J. A. (1993) Surface chemistry of ferrihydrite: Part I. EXAFS studies of the geometry of coprecipitated and adsorbed arsenate. Geochim. Cosmochim. Acta 57, 2251-2269.

Weber W. and Stumm W. (1965) Formation of a silicato-iron (III) complex in dilute aqueous solutions. J. Inorg. Nucl. Chem. 27, 237-239.

Wesolowski D. J., Palmer D. A., and Mesmer R. E. (1995) Measurements and control of $\mathrm{pH}$ in hydrothermal solutions. In Water-Rock Interaction (eds. Y. K. Kharaka and O. V. Chudaev), pp. 51-55. Balkema.

Winters G. V. and Buckley D. E. (1986) The influence of dissolved $\mathrm{FeSi}_{3} \mathrm{O}_{3}(\mathrm{OH})_{8}^{\circ}$ on chemical equilibria in pore waters from deep sea sediments. Geochim. Cosmochim. Acta 50, 277-288.

Winterer M. (1997) XAFS a data analysis program for material sciences. J. Physique IV 7, C2-243 (Abstr).

Xu S. and Harsh J. B. (1993) Labile and nonlabile aqueous silica in acid solutions: Relation to the colloidal fraction. J. Soil Sci. Soc. Am. 57, 1271-1277.

Zabinky S. Y., Rehr J. J., Ankudinov A. L., Albers R. S., and Eller M. J. (1995) Multiple scattering calculations of X-ray absorption spectra. Phys. Rev. B. 52, 2995-3009. 